University of Montana

ScholarWorks at University of Montana

Chemistry and Biochemistry Faculty

Publications

Chemistry and Biochemistry

6-17-2005

\title{
An Analysis of the Chemical Processes in the Smoke Plume from a Savanna Fire
}

Jorg Trentmann

University of Washington - Seattle Campus

Robert J. Yokelson

University of Montana - Missoula, bob.yokelson@umontana.edu

Peter V. Hobbs

University of Washington - Seattle Campus

Tanja Winterrath

Max Planck Institute for Chemistry

Ted J. Christian

University of Montana - Missoula

See next page for additional authors

Follow this and additional works at: https://scholarworks.umt.edu/chem_pubs

Part of the Biochemistry Commons, and the Chemistry Commons

Let us know how access to this document benefits you.

\section{Recommended Citation}

Trentmann, J., R. J. Yokelson, P. V. Hobbs, T. Winterrath, T. J. Christian, M. O. Andreae, and S. A. Mason (2005), An analysis of the chemical processes in the smoke plume from a savanna fire, J. Geophys. Res., 110, D12301, doi:10.1029/2004JD005628.

This Article is brought to you for free and open access by the Chemistry and Biochemistry at ScholarWorks at University of Montana. It has been accepted for inclusion in Chemistry and Biochemistry Faculty Publications by an authorized administrator of ScholarWorks at University of Montana. For more information, please contact scholarworks@mso.umt.edu. 


\section{Authors}

Jorg Trentmann, Robert J. Yokelson, Peter V. Hobbs, Tanja Winterrath, Ted J. Christian, Meinrat 0. Andreae, and Sherri A. Mason 


\title{
An analysis of the chemical processes in the smoke plume from a savanna fire
}

\author{
Jörg Trentmann, ${ }^{1,2}$ Robert J. Yokelson, ${ }^{3}$ Peter V. Hobbs, ${ }^{1}$ Tanja Winterrath, ${ }^{4,5}$ \\ Theodore J. Christian, ${ }^{3}$ Meinrat O. Andreae, ${ }^{4}$ and Sherri A. Mason ${ }^{6}$ \\ Received 24 November 2004; revised 18 March 2005; accepted 1 April 2005; published 17 June 2005.
}

[1] Photochemistry in young plumes from vegetation fires significantly transforms the initial fire emissions within the first hour after the emissions are injected into the atmosphere. Here we present an investigation of field measurements obtained in a smoke plume from a prescribed savanna fire during the SAFARI 2000 field experiment using a detailed photochemical box-dilution model. The dilution used in the model simulations was constrained by measurements of chemically passive tracers (e.g., $\mathrm{CO}$ ) near and downwind of the fire. The emissions of the dominant carbonaceous compounds, including oxygenated ones, were taken into account. The field measurements revealed significant production of ozone and acetic acid in the gas phase. The photochemical model simulations also predict ozone production, but significantly less than the measurements. The underestimation of the ozone production in the model simulations is likely caused by shortcomings of our current understanding of ozone photochemistry under the polluted conditions in this young smoke plume. Several potential reasons for this discrepancy are discussed. One possible cause could be the neglect of unmeasured emissions or surface reactions of $\mathrm{NO}_{2}$ with methanol or other hydrocarbons. In contrast to the field measurements, no significant production of acetic acid was simulated by the model. We know of no gas-phase reactions that cause the production of acetic acid on the timescale considered here. Though many processes were well-simulated by the model, there is a need for further research on some key photochemical processes within young plumes from biomass burning and the potential interactions between gas and the particulate phases. These fundamental photochemical processes may also be of importance in other polluted environments.

Citation: Trentmann, J., R. J. Yokelson, P. V. Hobbs, T. Winterrath, T. J. Christian, M. O. Andreae, and S. A. Mason (2005), An analysis of the chemical processes in the smoke plume from a savanna fire, J. Geophys. Res., 110, D12301, doi:10.1029/2004JD005628.

\section{Introduction}

[2] The burning of vegetation is a major source of atmospheric trace gases (e.g., carbon monoxide (CO), volatile organic compounds (VOC)) and aerosol particles [Crutzen and Andreae, 1990; Andreae and Merlet, 2001]. Savanna fires are responsible for the largest single contribution to the annual, global biomass burning emissions, with most savanna fires occurring in Africa [Dwyer et al., 2000].

\footnotetext{
${ }^{1}$ Department of Atmospheric Sciences, University of Washington, Seattle, Washington, USA.

${ }^{2}$ Now at Institute for Atmospheric Physics, Johannes GutenbergUniversity Mainz, Mainz, Germany.

${ }^{3}$ Department of Chemistry, University of Montana, Missoula, Montana USA.

${ }^{4}$ Department of Biogeochemistry, Max Planck Institute for Chemistry, Mainz, Germany.

${ }^{5}$ Now at Deutscher Wetterdienst, Offenbach am Main, Germany.

${ }^{6}$ Department of Chemistry, SUNY College at Fredonia, Fredonia, New York, USA.

Copyright 2005 by the American Geophysical Union. 0148-0227/05/2004JD005628
}

[3] The impact of fires on the composition of the earth's atmosphere on regional and global scales has been extensively documented by field observations and model simulations. A number of field experiments have focused on the impact of biomass burning emissions on atmospheric composition in different regions (e.g., the Southern Tropical Atlantic Region Experiment (STARE) [Andreae et al., 1996b], the Experiment for Regional Sources and Sinks of Oxidants (EXPRESSO) [Delmas et al., 1999], the Smoke, Clouds, and Radiation-Brazil experiment (SCAR-B) [Kaufman et al., 1998], and the Southern African Regional Science Initiative (SAFARI 2000) [Swap et al., 2002, 2003]). Field observations show that emissions from biomass burning can dominate the atmospheric composition in Africa and South America during the dry season [Artaxo et al., 1994; Anderson et al., 1996; Reid et al., 1998; Kirkman et al., 2000; Sinha et al., 2003b]. Satellite observations provide evidence that vegetation fires influence the atmospheric composition regularly on regional to global scales, especially in the tropical region [e.g., Fishman et al., 1991, 2003; Thompson et al., 2001; Torres et al., 2002; Bremer et al., 2004]. Field observations indicate that a significant 
fraction of enhanced ozone concentrations on regional scales are due to photochemical production of ozone in plumes from biomass burning before transport to the regional scale [Mauzerall et al., 1998; Kondo et al., 2004]. Several model studies confirm the impact of fire emissions on the level of primary (e.g., CO, aerosol particles) and secondary pollutants (e.g., ozone) in the atmosphere on regional and global scales on a regular basis [e.g., Jacob et al., 1992; Chatfield et al., 1998; Mauzerall et al., 1998; Lelieveld and Dentener, 2000; Marufu et al., 2000; Peters et al., 2002; Duncan et al., 2003a, 2003b]. Tropospheric ozone is a potent greenhouse gas, a contributor to air pollution, and influences the oxidation capacity of the atmosphere [Prather et al., 2001; Ramaswamy et al., 2001]. Understanding and predicting the atmospheric ozone concentration is therefore important.

[4] Photochemical production of tropospheric ozone and/ or acetic acid in young smoke plumes within the first hours after the smoke is injected into the atmosphere has been observed regularly [e.g., Evans et al., 1974, 1977; Radke et al., 1978; Stith et al., 1981; Hobbs et al., 1996, 2003; Goode et al., 2000; Takegawa et al., 2003; Jost et al., 2003; Yokelson et al., 2003a]. Unexpectedly low methanol $\left(\mathrm{CH}_{3} \mathrm{OH}\right)$ mixing ratios have been found in young cloudprocessed smoke suggesting a new heterogeneous methanol sink [Yokelson et al., 2003a; Tabazadeh et al., 2004]. Modifications of the physical, chemical, and optical properties of emitted smoke aerosol in young plumes from biomass burning have also been observed [Liousse et al., 1995; Hobbs et al., 1996; Magi and Hobbs, 2003; Hobbs et al., 2003; Li et al., 2003; Gao et al., 2003]. The formation of a convective cloud due to the fire-induced convection leads to limited aerosol scavenging and significant interaction between the cloud and the smoke particles [Radke et al., 1991, 2001; Reid et al., 1999; Andreae et al., 2004].

[5] While the impact of fire emissions on the large-scale atmospheric composition has been studied extensively with numerical models, young smoke plumes $(<6 \mathrm{~h}$ old $)$ from individual fires have received less attention. However, studies of young smoke plumes of precisely measured age offer insights into fundamental atmospheric processes. In addition, the pronounced changes of the primary fire emissions occurring in young plumes from biomass burning during the first hours after release into the atmosphere strongly modify the larger-scale impact of biomass burning. These processes should be considered as realistically as possible in large scale atmospheric models. Therefore, careful investigation of the processes in young smoke plumes using field measurements and model simulations has the potential to improve our understanding of fundamental atmospheric processes and the parameterization of fire emissions in larger scale models.

[6] Model studies of the photochemistry occurring in young smoke plumes have dealt with the potential impact of neglecting early plume chemistry in larger-scale models [Chatfield and Delany, 1990; Poppe et al., 1998] and the role of oxygenated volatile organic compounds (OVOC) [Mason et al., 2001]. Using a three-dimensional plume model, Trentmann et al. [2003a] studied the effects of the absorbing properties of the smoke aerosol on photochemistry. In a recent study, a box-dilution model constrained to field measurements from a wildfire in Namibia has been employed to investigate observed ozone and acetone production [Jost et al., 2003]. However, all of these studies suffer from limited field observations to constrain and evaluate the model results.

[7] As part of the dry season campaign of SAFARI 2000, the University of Washington's Convair-580 aircraft conducted 29 research flights from 10 August to 18 September 2000 in Southern Africa. For a detailed description of the various mission objectives and airborne instrumentation see Appendix A by P. V. Hobbs in Sinha et al. [2003a]. Here we focus on measurements obtained on 7 September 2000 (UW flight number 1834) in the plume from a prescribed savanna fire in the Timbavati Game Reserve (the Timbavati fire) near Kruger National Park, South Africa [Hobbs et al., 2003]. These measurements represent the most detailed observations to date of young fire emissions and their atmospheric evolution within the first hour. The focus of this work is to evaluate our current understanding of the photochemical processes in this smoke plume by comparing the measurements with results from a detailed photochemical box-dilution model. The extensive suite of measurements of chemical compounds allows a comprehensive evaluation of the model results. We present results from a reference simulation using emissions based on the field measurements and recent laboratory studies. By comparison of the model results with the field measurements we evaluate the success of the model in reproducing the measurements (e.g., the fast production of ozone and acetic acid, and the decay of hydrocarbons). Taking into account the uncertainty of the measurements, the descrepancies between the measurements and the model results will be interpreted as a lack of knowledge in our understanding of the chemical processes occuring under the polluted conditions of this smoke plume. Exploratory model simulations will be used to investigate the impact of a number of parameters on the model results and on the comparisons of the model results with the measurements. The results from this study, especially the inability of the model to reproduce the fast production of ozone and acetic acid, have potential implications for our understanding of atmospheric photochemistry, not only in young plumes from biomass burning, but also under similar polluted conditions.

\section{Observations}

[8] The plume from the Timbavati fire has been intensively studied and is described by Hobbs et al. [2003]. Following a description of the instruments used, we give a brief overview of the measurements relevant to the present study.

\subsection{Instrumentation}

[9] The Timbavati fire in South Africa was a prescribed savanna fire that burned an area of $\approx 1000$ ha between $0801 \mathrm{UTC}$ and $1130 \mathrm{UTC}$ (local time $=\mathrm{UTC}+2 \mathrm{~h}$ ) on 7 September 2000 at $24.38^{\circ} \mathrm{S}, 31.25^{\circ} \mathrm{E}$. The University of Washington's Convair-580 was used to measure the primary emissions from the fire and their evolution in the atmosphere between 0842 and 1036 UTC. The aircraft was equipped with instruments to measure chemical compounds, radiation, meteorological quantities, and aerosol properties (see Appendix A by P. V. Hobbs in Sinha et al. [2003a] for a full list of instruments). The present study focuses on data collected by the Airborne Fourier Transform 
Infrared Spectrometer (AFTIR) onboard the aircraft [Yokelson et al., 2003a].

[10] The AFTIR was deployed with a separate, specially coated inlet [Yokelson et al., 2003b] that directed ram air through a Pyrex multipass cell with an exchange time of 3$5 \mathrm{sec}$. An infrared spectrum was acquired every $0.83 \mathrm{sec}$ allowing the determination of mixing ratios of water vapor $\left(\mathrm{H}_{2} \mathrm{O}\right)$, carbon dioxide $\left(\mathrm{CO}_{2}\right), \mathrm{CO}$, and methane $\left(\mathrm{CH}_{4}\right)$. For the sampling of the smoke plume, the valves of the cell were closed near the peak of the $\mathrm{CO}$ absorption in the cell, and spectra were obtained for $2-3 \mathrm{~min}$. Averaging of these spectra allowed the retrieval of excess mixing ratios of a number of gases in the smoke plume compared to the ambient air. The gases were $\mathrm{H}_{2} \mathrm{O}, \mathrm{CO}_{2}, \mathrm{CO}$, nitric oxide (NO), nitrogen dioxide $\left(\mathrm{NO}_{2}\right), \mathrm{CH}_{4}$, ethene $\left(\mathrm{C}_{2} \mathrm{H}_{4}\right)$, acetylene $\left(\mathrm{C}_{2} \mathrm{H}_{2}\right)$, formaldehyde $(\mathrm{HCHO})$, methanol $\left(\mathrm{CH}_{3} \mathrm{OH}\right)$, acetic acid $\left(\mathrm{CH}_{3} \mathrm{COOH}\right)$, formic acid $(\mathrm{HCOOH})$, ammonia $\left(\mathrm{NH}_{3}\right)$, ozone $\left(\mathrm{O}_{3}\right)$, hydrogen cyanide $(\mathrm{HCN})$, and nitrous acid (HONO). The absolute uncertainty and the detection limit were 5-10 ppb for most compounds, but $15-20 \mathrm{ppb}$ for $\mathrm{NO}_{x}, \mathrm{HCHO}, \mathrm{CH}_{3} \mathrm{COOH}$, and $\mathrm{O}_{3}$. For a detailed description of the sampling strategy, the retrieval technique, and the sources of uncertainty see Yokelson et al. [2003a, and references therein].

[11] In addition to the AFTIR measurements, five stainless steel canisters were filled with air from the Timbavati plume (the sampling time per canister was $\approx 30 \mathrm{~s}$ ), and later analyzed at the University of California, Irvine, by gas chromatography (GC) with flame ionization detection (FID) and electron capture detection (ECD) for a number of compounds, including $\mathrm{CO}, \mathrm{CH}_{4}, \mathrm{C}_{2} \mathrm{H}_{4}, \mathrm{C}_{2} \mathrm{H}_{2}$, which are also used in the present study. Details of the analysis and the uncertainties can be found in Colman et al. [2001].

[12] In situ ozone measurements outside the plume were conducted up- and downwind of the fire using a TEI Model 49C instrument based on UV absorption.

\subsection{Measurements}

[13] The observational strategy involved extensive measurements near the fire to characterize the primary fire emissions and several measurements at different distances downwind of the fire to characterize the evolution of the smoke emissions in the atmosphere. During the course of the first hour after the emissions had been injected into the atmosphere, significant modifications of the initial fire emissions were observed [Hobbs et al., 2003].

[14] One of the main findings was the observation of fast photochemical production of ozone, leading to an enhancement ratio between ozone and carbon monoxide (defined as the ratio of the excess mixing ratio in the plume compared to the background atmosphere) of about $8.5 \%$ within the first hour after the emissions were injected into the atmosphere. Also the enhancement ratio between acetic acid and CO increased from about $1.5 \%$ over the fire to about $6 \%$ downwind of the fire. Similar ozone and acetic acid production rates were observed in two other smoke plumes from savanna fires during SAFARI 2000 [Yokelson et al., 2003a]. The increase in the ozone enhancement ratio was faster than observed in previous studies from other types of fires [Hobbs et al., 1996; Goode et al., 2000; Jost et al., 2003]. Other findings from the Timbavati plume include an estimate of the concentration of the $\mathrm{OH}$ radical based on the decrease of the enhancement ratios between a number of hydrocarbons and CO [Hobbs et al., 2003]. The hygroscopic properties of the smoke aerosol changed significantly within the first hour [Magi and Hobbs, 2003] potentially due to the observed conversion of $\mathrm{KCl}$ in young smoke particles to $\mathrm{K}_{2} \mathrm{SO}_{4}$ and $\mathrm{KNO}_{3}$ in aged smoke particles [Li et al., 2003]. Formation of particulate nitrate, sulfate, and organic compounds, and depletion of chlorine were also observed [ $\mathrm{Gao}$ et al., 2003].

[15] Tables 1 and 2 summarize the relevant measurements from the Timbavati plume. The background values used to calculate the mixing ratios from the measurement of the excess mixing ratio from the AFTIR are taken from AFTIR and canister measurements, where available. The average wind speed in the plume was $9.3 \mathrm{~m} \mathrm{~s}^{-1}$ for the samples collected between $500 \mathrm{~m}$ and $900 \mathrm{~m}$ a.g.l. (above ground level). Three AFTIR and one canister sample were taken at substantially higher elevation (between $1430 \mathrm{~m}$ and $1710 \mathrm{~m}$ a.g.l.), in the upper part of the plume, where the wind speed dropped to an average value of $7.3 \mathrm{~m} \mathrm{~s}^{-1}$. This was taken into account in the calculation of the age of the samples. The uncertainty of the wind speed was assumed to be $\pm 1.5 \mathrm{~m} \mathrm{~s}^{-1}$ taking into account measurement uncertainties and atmospheric variability. The wind speed used in the present study differs slightly from the the value used in the previous study of the Timbavati fire [Hobbs et al., 2003], but is considered more accurate based on later analysis.

[16] Figure 1 shows the vertical temperature and ozone profiles measured upwind of the Timbavati fire. A strong temperature inversion is present at a height of about $1400 \mathrm{~m}$. The ozone mixing ratio varies between $35 \mathrm{ppb}$ and $45 \mathrm{ppb}$. The corresponding profile for the relative humidity can be found in Hobbs et al. [2003, Figure 4].

[17] The measurements were not exactly performed in a Lagrangian fashion. However, from measurements of the $\Delta \mathrm{CO} / \Delta \mathrm{CO}_{2}$ and other enhancement ratios obtained near and downwind of the fire at different times, it was found that the emission characteristics changed much less than the downwind changes observed by Hobbs et al. [2003].

\section{Model Description}

[18] Major goals of this study include investigating the processes that lead to the observed increases in the ozone and acetic acid mixing ratios in the plume from the Timbavati fire, and to evaluate our understanding of the underlying photochemical processes. For this purpose we employ a photochemical box-dilution model, which includes an up-to-date representation of atmospheric photochemistry and mixing of the plume air with ambient air. An earlier version of the model has been used in a previous study of the photochemistry in another smoke plume observed during SAFARI 2000 in Namibia [Jost et al., 2003]. The photochemical model includes the atmospheric oxidation of the main compounds emitted from savanna fires [Christian et al., 2003], namely, $\mathrm{CO}, \mathrm{CH}_{4}$, ethane $\left(\mathrm{C}_{2} \mathrm{H}_{6}\right), \mathrm{C}_{2} \mathrm{H}_{4}, \mathrm{C}_{2} \mathrm{H}_{2}$, propane $\left(\mathrm{C}_{3} \mathrm{H}_{8}\right), \mathrm{C}_{3} \mathrm{H}_{6}$, 1-butene $\left(\mathrm{C}_{4} \mathrm{H}_{8}\right), \mathrm{HCHO}$, glycolaldehyde $\left(\mathrm{OHCH}_{2} \mathrm{CHO}\right)$, acetaldehyde $\left(\mathrm{CH}_{3} \mathrm{CHO}\right)$, methanol $\left(\mathrm{CH}_{3} \mathrm{OH}\right), \mathrm{HCOOH}$, $\mathrm{CH}_{3} \mathrm{COOH}$, isoprene $\left(\mathrm{C}_{5} \mathrm{H}_{8}\right)$, acetone $\left(\mathrm{CH}_{3} \mathrm{COCH}_{3}\right)$, acetol $\left(\mathrm{CH}_{3} \mathrm{COCH}_{2} \mathrm{OH}\right)$, methylvinylether $\left(\mathrm{CH}_{3} \mathrm{OCHCH}\right.$ or MVE), methylethylketone $\left(\mathrm{CH}_{3} \mathrm{COC}_{2} \mathrm{H}_{5}\right.$ or MEK), toluene 
Table 1. Mixing Ratios Measured in the Timbavati Plume Using Canister Samples (Numbered Samples) and AFTIR (Lettered Samples) ${ }^{\mathrm{a}}$

\begin{tabular}{lcccccc}
\hline Sample & $\begin{array}{c}\text { Distance From } \\
\text { Fire, km }\end{array}$ & $\begin{array}{c}\text { Age, } \\
\text { min }\end{array}$ & $\begin{array}{c}\mathrm{CO}, \\
\mathrm{ppb}\end{array}$ & $\begin{array}{c}\mathrm{CH}_{4}, \\
\mathrm{ppm}\end{array}$ & $\begin{array}{c}\mathrm{C}_{2} \mathrm{H}_{2}, \\
\mathrm{ppb}\end{array}$ & $\begin{array}{c}\mathrm{C}_{2} \mathrm{H}_{4}, \\
\mathrm{ppb}\end{array}$ \\
\hline Ambient & & & $182(\mathrm{~A})$ & $1.774(\mathrm{~A})$ & $0.49(\mathrm{C})$ & $0.32(\mathrm{C})$ \\
$\mathrm{a}$ & 0.0 & 0.0 & 5920 & 2.119 & 19.49 & 91.32 \\
2 & 0.2 & 0.4 & 3875 & 1.902 & 12 & 35 \\
1 & 1.0 & 1.8 & 3506 & 1.866 & 12 & 32 \\
$\mathrm{~b}$ & 1.7 & 3.0 & 4206 & 1.988 & 14.49 & 58.32 \\
$\mathrm{~h}$ & 2.1 & 3.8 & 1774 & 1.841 & bdl & 20.21 \\
$\mathrm{~d}$ & 3.3 & 5.9 & 1093 & 1.854 & bdl & 12.32 \\
3 & 4.9 & 8.8 & 1492 & 1.789 & 4.8 & 12 \\
$\mathrm{c}$ & 9.4 & 16.8 & 1958 & 1.883 & 6.49 & 21.32 \\
$e$ & 15.5 & 35.4 & 1224 & 1.829 & $b d l$ & 31.32 \\
$f$ & 18.4 & 42.0 & 1807 & 1.891 & $b d l$ & 44.32 \\
$g$ & 20.5 & 46.8 & 1136 & 1.834 & $b d l$ & 29.32 \\
4 & 20.8 & 47.5 & 2268 & 1.817 & 7.79 & 16 \\
5 & 26.2 & 47.0 & 1075 & 1.774 & 3.59 & 6 \\
$\mathrm{i}$ & 27.8 & 49.8 & 731 & 1.807 & bdl & bdl \\
$\mathrm{j}$ & 28.5 & 51.1 & 826 & 1.802 & bdl & bdl \\
$\mathrm{k}$ & 31.3 & 56.1 & 608 & 1.795 & bdl & bdl \\
\hline
\end{tabular}

${ }^{\mathrm{a}}$ Here bdl, below detection limit. Ambient mixing ratios taken from AFTIR measurements (A) and canister samples (C), measured by D. Blake, UCI; highlighted samples were taken in the upper part of the plume; the numbering of the samples is the same as that used by Hobbs et al. [2003].

$\left(\mathrm{C}_{6} \mathrm{H}_{5} \mathrm{CH}_{3}\right)$, phenol $\left(\mathrm{C}_{6} \mathrm{H}_{5} \mathrm{OH}\right)$, furan $\left(\mathrm{C}_{4} \mathrm{H}_{4} \mathrm{O}\right)$, 2-methylfuran $\left(\mathrm{C}_{5} \mathrm{H}_{6} \mathrm{O}\right), \mathrm{NO}, \mathrm{NO}_{2}, \mathrm{HONO}, \mathrm{HCN}$, sulfur dioxide $\left(\mathrm{SO}_{2}\right)$, ammonia $\left(\mathrm{NH}_{3}\right)$, and molecular hydrogen $\left(\mathrm{H}_{2}\right)$. The photochemical model has been expanded substantially compared to the study of Jost et al. [2003] to account for the recently reported more comprehensive set of emissions from savanna fires [Christian et al., 2003]. The above VOC were estimated to account for $\approx 70 \%$ of the carbon emitted as VOC [Christian et al., 2003].

[19] The selection of reaction rate coefficients is mostly based on recent evaluations [Sander et al., 2003; Atkinson et al., 1997, 2004] with some updates based on recent laboratory measurements. The rate coefficient for the $\mathrm{OH}$ reaction with CO is taken from McCabe et al. [2001]. Recent measurements of the reaction rates for the $O\left({ }^{1} \mathrm{D}\right)$ radical and subsequent formation of the $\mathrm{OH}$ radical were employed [Dunlea and Ravishankara, 2004a, 2004b]. The temperature-dependent rate coefficient for the reaction of acetic acid with $\mathrm{OH}$ was adopted [Butkovskaya et al., 2004]. The reaction rate and the products for the OH-oxidation of acetone are taken from recent studies [Gierczak et al., 2003; Talukdar et al., 2003], Oxidation of isoprene is described based on the Mainzer Isoprene Mechanism (MIM) [Pöschl et al., 2000]. The rate coefficient for the $\mathrm{OH}$-induced oxidation of phenol is taken from Calvert et al. [2001], the resulting products and subsequent oxidation steps are based on recent works [Platz et al., 1998; Olariu et al., 2000, 2002; Berndt and Böge, 2003]. The oxidation of toluene was included as presented in Wagner et al. [2003]. The atmospheric oxidation of methyl ethyl ketone was taken from Bonn et al. [2004]. Oxidation of methyl vinyl ether and the resulting methyl formate was taken into account [Grosjean and Williams, 1992; Calvé et al., 1997; Good et al., 1999; Klotz et al., 2004]. Three heterogeneous reactions on smoke aerosol are included in the standard simulations: the uptake of $\mathrm{NH}_{3}$, hydrolysis of $\mathrm{N}_{2} \mathrm{O}_{5}$, and formation of $\mathrm{HONO}$ from $\mathrm{NO}_{2}$. The reaction rates are calculated as firstorder rate coefficients $\mathrm{k}_{\text {het }}=\left(\frac{a}{D_{\mathrm{s}}}+\frac{4}{\gamma c}\right)^{-1} \times A$, where $\mathrm{a}$ is the mass median radius of the aerosol particles, $\mathrm{D}_{g}$ is the gasphase molecular diffusion coefficient in air, $\gamma$ is the uptake coefficient, $\mathrm{c}$ the mean molecular speed, and $\mathrm{A}$ the aerosol surface area $[J a c o b, 2000]$. Photolysis frequencies are calculated with the method of Landgraf and Crutzen [1998], using the Practical Improved Flux Method (PIFM) [Zdunkowski et al., 1982] for the simulation of the actinic flux under clear sky conditions. For the photolysis reactions for which the required polynomial coefficients are not available, linear correlations with the photolysis frequencies for other reactions were used [von Kuhlmann et al., 2003]. The full reaction mechanism includes about 255 chemical compounds and about 600 reactions. The Kinetic PreProcessor (KPP) [Damian et al., 2002; Sandu et al., 2003] was used to solve the set of differential equations for the chemical species.

[20] Mixing of plume air with ambient air is the main reason for the decrease of the mixing ratios of the fire emissions in the plume with distance from the fire. In the model simulations, the dilution for each compound is assumed to be proportional to the product of the gradient

Table 2. Mixing Ratios Measured in the Timbavati Plume Using AFTIR ${ }^{\mathrm{a}}$

\begin{tabular}{lccccccccc}
\hline Sample & $\mathrm{HCHO}, \mathrm{ppb}$ & $\mathrm{CH}_{3} \mathrm{OH}, \mathrm{ppb}$ & $\mathrm{HCOOH}, \mathrm{ppb}$ & $\mathrm{CH}_{3} \mathrm{COOH}, \mathrm{ppb}$ & $\mathrm{HCN}, \mathrm{ppb}$ & $\mathrm{NO}, \mathrm{ppb}$ & $\mathrm{NO}_{2}, \mathrm{ppb}$ & $\mathrm{O}_{3}, \mathrm{ppb}$ & $\Delta \mathrm{O}_{3} / \Delta \mathrm{CO}, \%$ \\
\hline Ambient & 0.855 & 2.5 & 0.225 & 0.6 & 0 & 0.3 & 0.456 & $42^{\mathrm{b}}$ & \\
$\mathrm{a}$ & 109.9 & 86 & 33 & 75 & 37 & 57.3 & 137.5 & -10 & -0.9 \\
$\mathrm{~b}$ & 74.9 & 74 & 33 & 58 & 29 & 52.3 & 123.5 & -10 & -1.3 \\
$\mathrm{~h}$ & 25.9 & 19 & 6 & 53 & bdl & bdl & 51.5 & bdl & bdl \\
$\mathrm{d}$ & 20.9 & 20 & $\mathrm{bdl}$ & 23 & 9 & bdl & bdl & 30 & 1.0 \\
$\mathrm{c}$ & 16.9 & 28 & 17 & 14 & 18 & bdl & 51.5 & 64 & 1.0 \\
$e$ & 31.9 & 10 & 11 & 30 & 8 & $b d l$ & $b d l$ & 99 & 5.5 \\
$f$ & 37.9 & $b d l$ & $b d l$ & 71 & 18 & $b d l$ & $b d l$ & 134 & 5.7 \\
$g$ & 31.9 & 7 & 5 & 36 & 11 & $b d l$ & $b d l$ & 124 & 8.6 \\
$\mathrm{i}$ & 10.9 & bdl & bdl & 27 & bdl & bdl & 6.5 & 73 & 5.7 \\
$\mathrm{j}$ & 10.9 & 9 & bdl & 35 & bdl & bdl & bdl & 96 & 8.4 \\
$\mathrm{k}$ & 20.9 & 5 & bdl & 32 & bdl & bdl & bdl & 61 & 4.6 \\
\hline
\end{tabular}

${ }^{a}$ Here bdl, below detection limit. Ambient mixing ratios taken from global model simulations using the GEOS-CHEM model, provided by Lyatt Jaeglé ( $\left.\mathrm{HCHO}, \mathrm{NO}_{x}\right)$ and the MATCH-MPICH model, provided by Rolf von Kuhlmann $\left(\mathrm{CH}_{3} \mathrm{OH}, \mathrm{HCOOH}\right.$, $\mathrm{CH}_{3} \mathrm{COOH}$ ).

${ }^{\mathrm{b}}$ The ambient ozone mixing ratio is based on airborne in situ measurements obtained upwind the fire using the TEI Model 49C. The numbering of the samples is the same as that used by Hobbs et al. [2003]. 


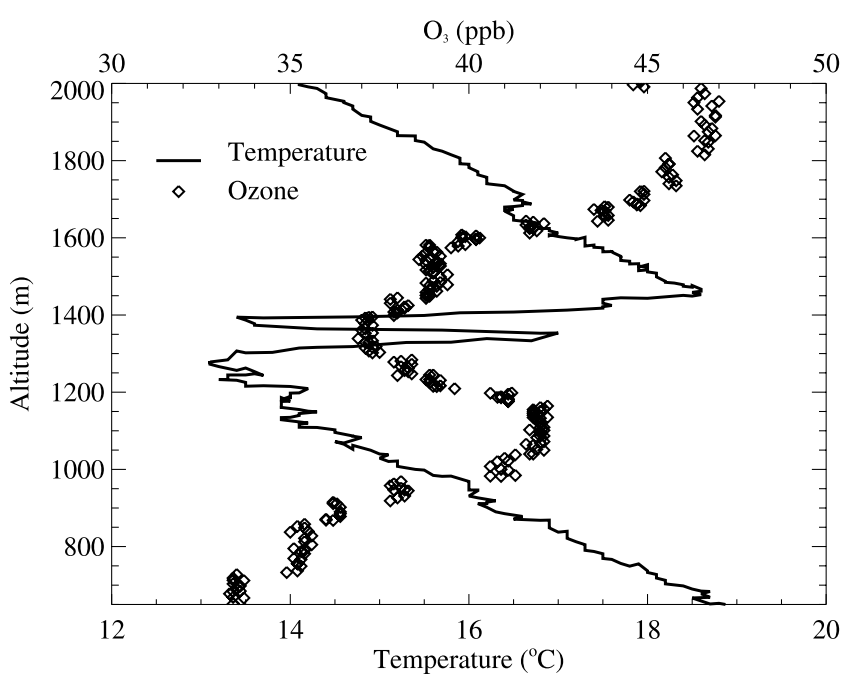

Figure 1. Vertical temperature and ozone profile measured upwind of the Timbavati fire from 0829 to 0840 UTC.

of the concentration between the plume and the ambient air and the normalized change of the plume width [Poppe et al., 1998; Mason et al., 2001]. For the calculation of the temporal development of the plume width, we follow the approach of Sillman et al. [1990], which has been used in other studies of plumes from biomass burning [Jacob et al., 1992; Mauzerall et al., 1998; Mason et al., 2001; Jost et al., 2003]. The mixing ratios in the ambient air are assumed to remain constant over the time period of the model simulations. The dilution coefficients are derived from observations and are presented in section 5.1.

\section{Model Initialization}

[21] Table 3 presents the ambient mixing ratios, the initial mixing ratios of $\mathrm{CO}$ and $\mathrm{O}_{3}$ in the plume, and the emission ratios used in the model simulations. The initial $\mathrm{CO}$ mixing ratio was calculated as the average of samples (a) and (2) from Table 1. Negative excess ozone mixing ratios were measured near the fire in the Timbavati plume [Hobbs et al., 2003], indicating significant depletion of ozone via the reaction with the emitted NO. To account for this effect, the initial ozone mixing ratio was set to $5 \mathrm{ppb}$ (i.e., $37 \mathrm{ppb}$ lower than the assumed ambient mixing ratio). Due to rapid mixing the simulated ozone mixing ratio in the plume quickly reaches the ambient value and the model results do not depend on the value of the initial ozone mixing ratio. If available, the emission ratios were taken from measurements obtained in the Timbavati plume. In addition, data from a recent laboratory study based on the burning of African savanna fuels was used [Christian et al., 2003]. The ambient mixing ratios were taken from measurements obtained in the vicinity of the Timbavati plume, if available. When no field measurements of ambient air were available, results from global model simulations (GEOS-CHEM [Bey et al., 2001; Sinha et al., 2004] and MATCH-MPIC [von Kuhlmann et al., 2003]) were used. The initial particle number concentration was set to $90,000 \mathrm{~cm}^{-3}$ based on field measurements [Hobbs et al., 2003], the mass median surface area and particle radius were assumed to be $2 \times$ $10^{-9} \mathrm{~cm}^{2}$ and $100 \mathrm{~nm}$, respectively, based on particle size distribution measurements from another wildland fire during SAFARI 2000 [Haywood et al., 2003].

[22] The pressure, temperature, and relative humidity in the model simulation were set to $900 \mathrm{hPa}, 288 \mathrm{~K}$, and $45 \%$, respectively, based on aircraft measurements. Variation of these parameters within a reasonable range did not lead to a significant change in the model results. Surface albedo was set to $5 \%$, consistent with measurements from the Solar Spectral Flux Radiometer (SSFR) aboard the Convair-580 [Pilewskie et al., 2003]. The diurnal variation of the solar zenith angle was calculated for $24.38^{\circ} \mathrm{S}, 31.25^{\circ} \mathrm{E}$ on 7 September 2000. Model simulations were started at 1045 local time ( $=0845$ UTC). Photolysis frequencies were calculated using the tropical US-Standard atmosphere scaled to a total ozone column of 288 DU based on TOMS observations (available at http://toms.gsfc.nasa.gov/ index.html). The impact of the smoke aerosol on the photolysis frequency was not taken into account in our standard simulations, because of the large associated uncertainties. In section 6.1, we present model results that include estimates for the radiative effects of the smoke aerosol based on measurements from the SSFR.

\section{Model Results and Comparisons With Measurements}

[23] In this section we present results from the model simulations and compare these results with the measurements.

\subsection{Passive Tracers}

[24] To realistically represent the dilution of the plume through mixing with the ambient air, the simulated dilution is chosen in such a way that the model is able to reproduce the observations of a passive tracer (e.g., CO). Two parameters, the initial width of the plume $\left(\mathrm{y}_{0}\right.$ in $\left.\mathrm{m}\right)$ and the horizontal diffusion coefficient $\left(\mathrm{K}_{y}\right.$ in $\left.\mathrm{m}^{2} \mathrm{~s}^{-1}\right)$, determine the dilution in the model simulations. For the simulations presented here, the initial width of the plume was held constant at $2 \mathrm{~km}$, based on the observed width of the fire front [Hobbs et al., 2003], and $\mathrm{K}_{y}$ was used to scale the simulated dilution.

[25] Figure 2 shows the simulated $\mathrm{CO}$ mixing ratio for three different values of $\mathrm{K}_{y}\left(2500 \mathrm{~m}^{2} \mathrm{~s}^{-1}, 7000 \mathrm{~m}^{2} \mathrm{~s}^{-1}\right.$, and $15000 \mathrm{~m}^{2} \mathrm{~s}^{-1}$ ) along with the measurements from the AFTIR and from the canister samples. The comparison between the measurements and the model simulations suggests that a value of $7000 \mathrm{~m}^{2} \mathrm{~s}^{-1}$ for $\mathrm{K}_{y}$ results in a reasonable representation of the average $\mathrm{CO}$ mixing ratio downwind the fire. However, especially for the measurements performed in the upper part of the plume (samples e, $\mathrm{f}, \mathrm{g}$, and 4 in Table 1 and the solid symbols in Figure 2), a dilution coefficient of $\mathrm{K}_{y}=2500 \mathrm{~m}^{2} \mathrm{~s}^{-1}$ results in a better agreement between the observations and the model simulations. A value of $\mathrm{K}_{y}=15000 \mathrm{~m}^{2} \mathrm{~s}^{-1}$ is used as an upper estimate for the dilution coefficient.

[26] Figure 3 shows the mixing ratios of $\mathrm{CH}_{4}, \mathrm{C}_{2} \mathrm{H}_{2}$, and HCN (Figures $3 a-3 c$ ) and their enhancement ratios with respect to $\mathrm{CO}$ (Figures 3d-3f) in the Timbavati plume. These species are passive tracers on the timescale considered here, that is, their concentrations are not modified by known chemical reactions. In all cases, the model simulations match the observations well, with a tendency for the observations performed in the upper part of the plume (solid 
Table 3. Mixing Ratios of the Ambient Air, the Initial Mixing Ratios of $\mathrm{CO}$ and $\mathrm{O}_{3}$ in the Smoke Plume, and the Emission Ratios Used in the Model Simulations ${ }^{\mathrm{a}}$

\begin{tabular}{|c|c|c|c|c|c|}
\hline Compound & Ambient Mixing Ratio, ppb & Emission Ratio, $\Delta \mathrm{X} / \Delta \mathrm{CO}, \%$ & Compound & Ambient Mixing Ratio, ppb & Emission Ratio $\Delta \mathrm{X} / \Delta \mathrm{CO}, \%$ \\
\hline $\mathrm{CO}$ & $182 \mathrm{ppb}^{1}$ & $4.9 \mathrm{ppm}^{1}$ & $\mathrm{C}_{3} \mathrm{H}_{6} \mathrm{O}_{2}$ & $0 \mathrm{ppt}$ & $0.33^{5}$ \\
\hline $\mathrm{O}_{3}$ & $42 \mathrm{ppb}^{1}$ & $5 \mathrm{ppb}^{1}$ & $\mathrm{C}_{6} \mathrm{H}_{5} \mathrm{OH}$ & $0 \mathrm{ppt}$ & $0.346^{5}$ \\
\hline $\mathrm{CH}_{4}$ & $1.774 \mathrm{ppm}^{1}$ & $5.83^{2}$ & $\mathrm{C}_{4} \mathrm{H}_{4} \mathrm{O}$ & $0 \mathrm{ppt}$ & $0.128^{5}$ \\
\hline $\mathrm{C}_{2} \mathrm{H}_{6}$ & $860 \mathrm{ppt}^{3}$ & $0.3^{3}$ & $\mathrm{C}_{5} \mathrm{H}_{6} \mathrm{O}$ & $0 \mathrm{ppt}$ & $0.128^{7}$ \\
\hline $\mathrm{C}_{2} \mathrm{H}_{4}$ & $320 \mathrm{ppt}^{1}$ & $1.6^{2}$ & $\mathrm{C}_{6} \mathrm{H}_{5} \mathrm{CH}_{3}$ & $0 \mathrm{ppt}$ & $0.078^{5}$ \\
\hline $\mathrm{C}_{2} \mathrm{H}_{2}$ & $490 \mathrm{ppt}^{1}$ & $0.34^{2}$ & $\mathrm{C}_{5} \mathrm{H}_{8}$ & $0 \mathrm{ppt}$ & $0.02^{3}$ \\
\hline $\mathrm{C}_{3} \mathrm{H}_{8}$ & $110 \mathrm{ppt}^{3}$ & $0.0525^{3}$ & $\mathrm{C}_{3} \mathrm{H}_{6} \mathrm{O}$ & $0 \mathrm{ppt}$ & $0.166^{5}$ \\
\hline $\mathrm{C}_{3} \mathrm{H}_{6}$ & $31 \mathrm{ppt}^{3}$ & $0.235^{3}$ & $\mathrm{CH}_{3} \mathrm{COC}_{2} \mathrm{H}_{5}$ & $0 \mathrm{ppt}$ & $0.286^{8}$ \\
\hline $\mathrm{C}_{4} \mathrm{H}_{8}$ & $0 \mathrm{ppt}$ & $0.033^{3}$ & $\mathrm{NO}$ & $296 \mathrm{ppt}^{9}$ & $1.16^{2}$ \\
\hline $\mathrm{HCHO}$ & $855 \mathrm{ppt}^{1}$ & $1.87^{3}$ & $\mathrm{NO}_{2}$ & $460 \mathrm{ppt}^{9}$ & $2.6^{2}$ \\
\hline $\mathrm{OHCH}_{2} \mathrm{CHO}$ & $304 \mathrm{ppt}^{4}$ & $0.316^{5}$ & HONO & $0 \mathrm{ppt}$ & $0.122^{10}$ \\
\hline $\mathrm{CH}_{3} \mathrm{CHO}$ & $304 \mathrm{ppt}^{6}$ & $0.678^{5}$ & $\mathrm{HCN}$ & $0 \mathrm{ppt}$ & $0.72^{2}$ \\
\hline $\mathrm{CH}_{3} \mathrm{OH}$ & $2.5 \mathrm{ppb}^{11}$ & $1.45^{2}$ & $\mathrm{~N}_{2} \mathrm{O}$ & $315 \mathrm{ppb}^{12}$ & $0.21^{13}$ \\
\hline $\mathrm{HCOOH}$ & $225 \mathrm{ppt}^{11}$ & $0.64^{2}$ & $\mathrm{SO}_{2}$ & $10 \mathrm{ppb}^{3}$ & $1.28^{5}$ \\
\hline $\mathrm{CH}_{3} \mathrm{COOH}$ & $600 \mathrm{ppt}^{11}$ & $1.46^{2}$ & $\mathrm{NH}_{3}$ & $478 \mathrm{ppt}^{6}$ & $0.16^{2}$ \\
\hline $\mathrm{CH}_{3} \mathrm{COCH}_{3}$ & $3.6 \mathrm{ppb}^{6}$ & $0.128^{5}$ & $\mathrm{H}_{2}$ & $540 \mathrm{ppb}^{14}$ & $25.7^{5}$ \\
\hline
\end{tabular}

${ }^{\mathrm{a}} \mathrm{For} \mathrm{CO}$ and $\mathrm{O}_{3}$ the initial mixing ratios in the smoke plume are given. 1, Taken from Tables 1 and 2; 2, taken from Yokelson et al. [2003a] for the Timbavati fire; 3, taken from Hobbs et al. [2003]; 4, the ambient mixing ratio of $\mathrm{OHCH}_{2} \mathrm{CHO}$ was assumed to be identical to $\mathrm{CH}_{3} \mathrm{CHO}$; 5 , taken from Christian et al. [2003]; 6, taken from a global model simulation using the GEOS-CHEM model, provided by Lyatt Jaeglé; 7, emission factor of 2-methylfuran is assumed to be the same as for furan, based on Andreae et al. [1996a]; 8, R. Yokelson, personal communication; 9 , ambient $\mathrm{NO}^{2}$ and $\mathrm{NO}_{2}$ mixing ratios based on $\mathrm{NO}_{x}$ mixing ratio from the GEOS-CHEM model assuming photochemical equilibrium, provided by Lyatt Jaeglé; 10, emission ratio for HONO based on analysis of spectra from AFTIR sample (a), T. Christian, personal communication; 11, ambient mixing ratios for $\mathrm{CH}_{3} \mathrm{OH}, \mathrm{HCOOH}$, and $\mathrm{CH}_{3} \mathrm{COOH}$ are provided by Rolf von Kuhlmann based on results from the MATCH-MPIC model; 12, ambient $\mathrm{N}_{2} \mathrm{O}$ mixing ratio taken from Prather et al. [2001]; 13, taken from Andreae and Merlet [2001]; 14, ambient mixing ratio for molecular hydrogen taken from Hauglustaine and Ehhalt [2002].

symbols) to be better reproduced with a lower modeled dilution. As expected, no change in the enhancement ratio between the passive tracers and $\mathrm{CO}$ along the plume was observed or simulated. We note that the values for the $\Delta \mathrm{CH}_{4} / \Delta \mathrm{CO}$ ratio determined from the canister samples are slightly lower than the corresponding values determined from the AFTIR measurements. The same conclusion can be drawn from Sinha et al. [2003a], however, the difference is not statistically significant.

\subsection{Ozone and Nitrogen Oxides}

[27] Figure 4 presents the simulated and measured ozone mixing ratio and the $\Delta \mathrm{O}_{3} / \Delta \mathrm{CO}$ ratio in the Timbavati plume. The reported values of the ozone mixing ratio in the plume were determined by adding the ambient ozone mixing ratio of $42 \mathrm{ppb}$, as measured by the in situ UV absorption instrument, to the measured excess ozone mixing ratio by the AFTIR. This procedure leads to negative values of the ozone mixing ratio close to the fire, with error bars stretching to positive values. The model simulations show a much smaller increase in the ozone mixing ratio and the $\Delta \mathrm{O}_{3} / \Delta \mathrm{CO}$ ratio during the first hour after emission than the observations. The measured ozone mixing ratio increases up to a value of about $130 \mathrm{ppb}$ at about 40 minutes, while the model yields only about $70 \mathrm{ppb}$ (for the simulation with the low dilution coefficient). The model also fails to reproduce the measured increase in the $\Delta \mathrm{O}_{3} / \Delta \mathrm{CO}$ ratio up to a value of about $8.5 \%$. The model results predict a $\Delta \mathrm{O}_{3} / \Delta \mathrm{CO}$ ratio between $4 \%$ and $5 \%$, with the lower value corresponding to the use of the lowest dilution coefficient. This discrepancy suggests that one or more important processes for the photochemical formation of ozone in the Timbavati plume are not included in the simulations.

[28] Figure 5 presents the comparison between the measured and simulated mixing ratios for $\mathrm{NO}$ and $\mathrm{NO}_{2}$. We do not present enhancement ratios for these compounds due to the scarcity of data downwind of the fire for these compounds. We include, however, measurements that were below the detection limit of the AFTIR instrument (20 ppb for $\mathrm{NO}$ and $\mathrm{NO}_{2}$ ). The model is able to reproduce the observed $\mathrm{NO}$ mixing ratio, but predicts $\mathrm{NO}_{2}$ mixing ratios downwind of the fire that are above the detection limit of the AFTIR, in contrast to the measurements. This overestimation is especially striking for the measurements per-

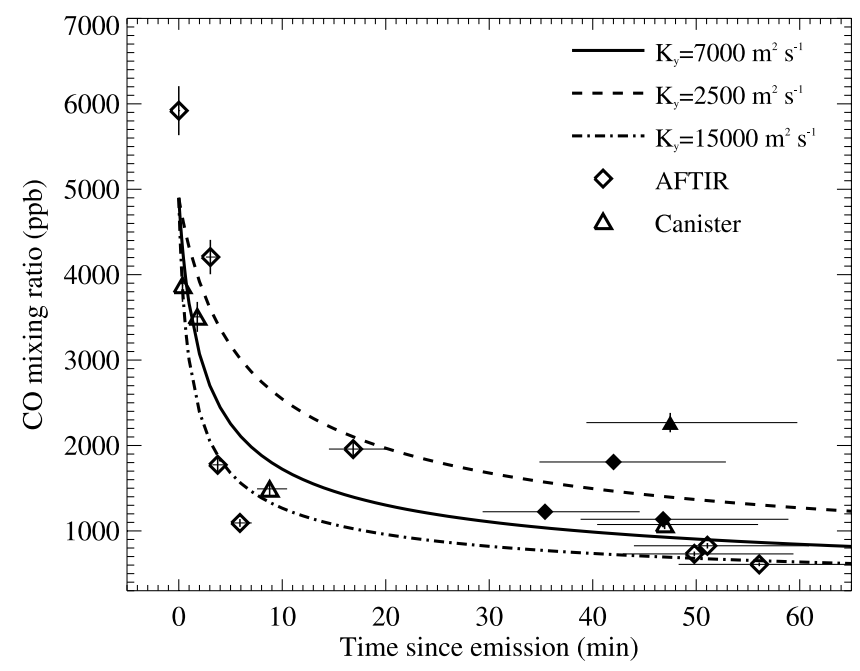

Figure 2. Measured and simulated mixing ratio of $\mathrm{CO}$ in the Timbavati plume. The lines represent results from three model simulations using $\mathrm{K}_{y}$ values of $7000 \mathrm{~m}^{2} \mathrm{~s}^{-1}$, $2500 \mathrm{~m}^{2} \mathrm{~s}^{-1}$, and $15000 \mathrm{~m}^{2} \mathrm{~s}^{-1}$, respectively. AFTIR measurements are represented by diamonds, triangles represent canister samples. The solid symbols represent measurements obtained in the upper part of the plume. Horizontal bars represent the uncertainty in the age of the measurements based on uncertainties in the measured wind speed. 

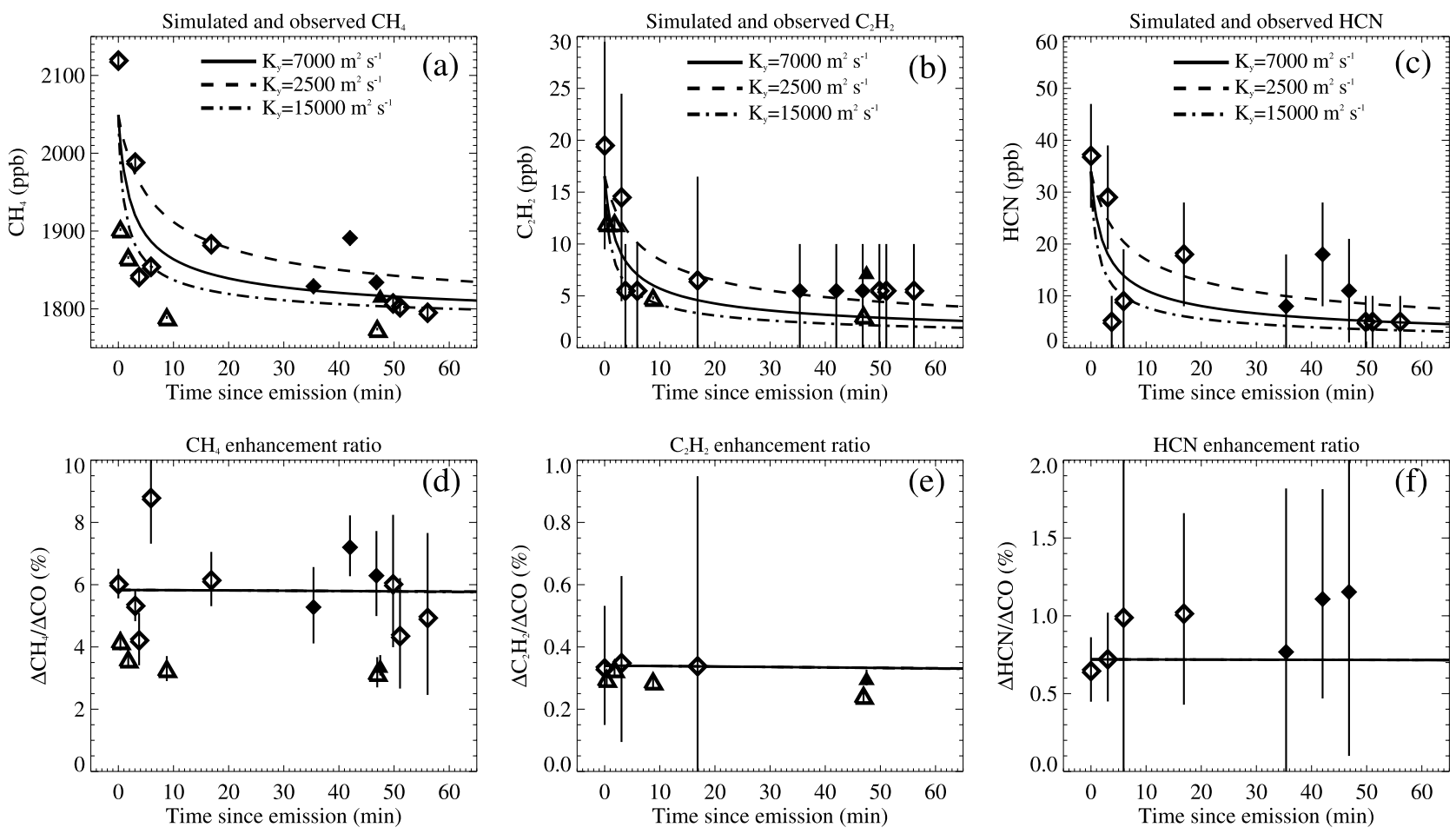

Figure 3. Measured and simulated mixing ratios and enhancement ratios with respect to $\mathrm{CO}$ of (a and d) $\mathrm{CH}_{4}$, (b and e) $\mathrm{C}_{2} \mathrm{H}_{4}$, and (c and f) $\mathrm{HCN}$ in the Timbavati plume. The lines represent model simulations using three different values of $\mathrm{K}_{y}$. AFTIR measurements are represented by diamonds, triangles represent canister samples. The solid symbols represent measurements obtained in the upper part of the plume. Horizontal error bars (not shown) are identical to those shown in Figure 2.

formed in the upper part of the plume (solid diamonds in Figure 5). Here the model predicts $\mathrm{NO}_{2}$ mixing ratios of more than $30 \mathrm{ppb}$ (dashed line), while $\mathrm{NO}_{2}$ was not detected in the AFTIR measurements, indicating an atmospheric mixing ratio in the Timbavati plume well below $20 \mathrm{ppb}$. This discrepancy suggests a missing loss process for $\mathrm{NO}_{x}$ in the model simulations, or significantly lower initial $\mathrm{NO}_{x}$ emissions for these samples.

\subsection{Organic Compounds}

[29] Figure 6 shows the measured and simulated $\mathrm{C}_{2} \mathrm{H}_{4}$, $\mathrm{HCHO}$, and $\mathrm{CH}_{3} \mathrm{OH}$ mixing ratios and their enhancement ratios with respect to $\mathrm{CO}$ in the Timbavati plume. The AFTIR measurements of the $\mathrm{C}_{2} \mathrm{H}_{4}$ mixing ratio and enhancement ratio in the upper part of the plume (solid diamonds in Figures 6a and 6d) yielded significantly higher values than the canister measurements and the model simulations. The measured high enhancement ratio (about $3 \%$ for the high-plume measurements compared to $1.5 \%$ for the measurements taken near the fire) is particularly striking. As secondary production of ethene in the plume is unlikely (but cannot be ruled out), this finding suggests that the smoke in the upper levels of the plume had a different emission ratio for ethene (and perhaps other VOC) than the
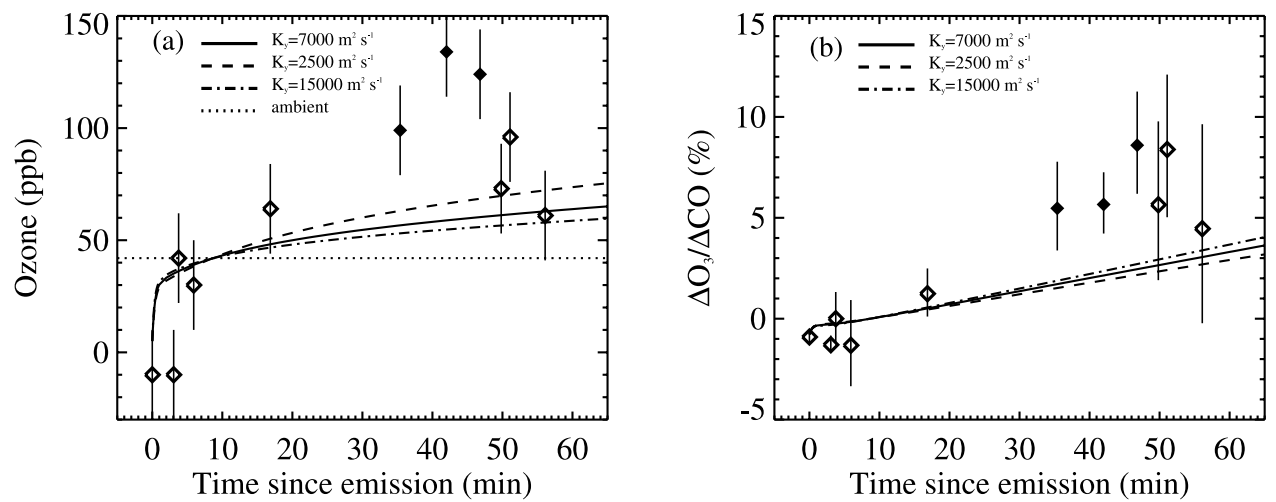

Figure 4. Measured and simulated (a) ozone mixing ratios and (b) ozone enhancement ratios with respect to $\mathrm{CO}$ in the Timbavati plume. The lines represent model simulations using three different values of $\mathrm{K}_{y}$. AFTIR measurements are represented by diamonds. The solid symbols represent measurements obtained in the upper part of the plume. Horizontal error bars (not shown) are identical to those shown in Figure 2. 

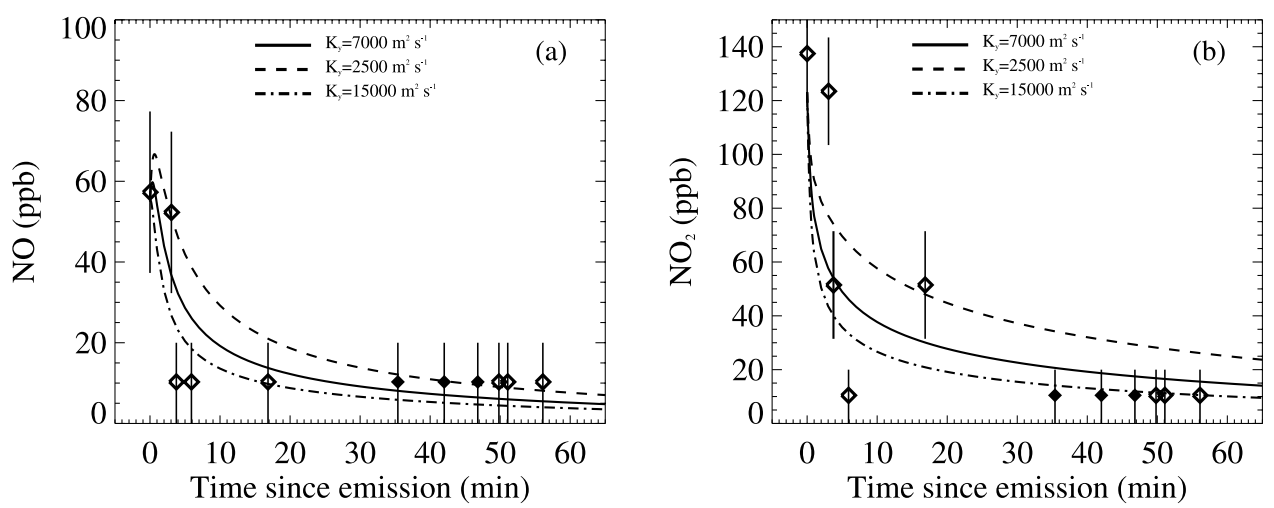

Figure 5. Measured and simulated mixing ratios of (a) $\mathrm{NO}$, and (b) $\mathrm{NO}_{2}$ in the Timbavati plume. The lines represent model simulations using three different values of $\mathrm{K}_{y}$. AFTIR measurements are represented by diamonds. The solid symbols represent measurements obtained in the upper part of the plume. Horizontal error bars (not shown) are identical to those shown in Figure 2.

average plume. We also note that the mixing ratios and enhancement ratios of ethene with respect to CO close to the fire, as measured by the AFTIR, are higher than those measured by gas chromatography from the canister samples ( $1.5 \%$ compared to $0.9 \%)$. This has been noted for the full dataset from SAFARI 2000 [Sinha et al., 2003a]. A recent laboratory study did not find a significant difference between the $\Delta \mathrm{C}_{2} \mathrm{H}_{4} / \Delta \mathrm{CO}$ ratios determined by these different methods [Christian et al., 2004]. The slightly different sampling times between the AFTIR and the canister in the aircraft measurements might therefore be responsible for the variability between these two measurement techniques.

[30] For $\mathrm{HCHO}$, the results from the model simulations compare well with the measurements of the mixing ratios and the enhancement ratios with respect to $\mathrm{CO}$ in the Timbavati plume, indicating no major lack of understanding in the formaldehyde photochemistry in smoke plumes on these timescales. The measurements obtained in the higher
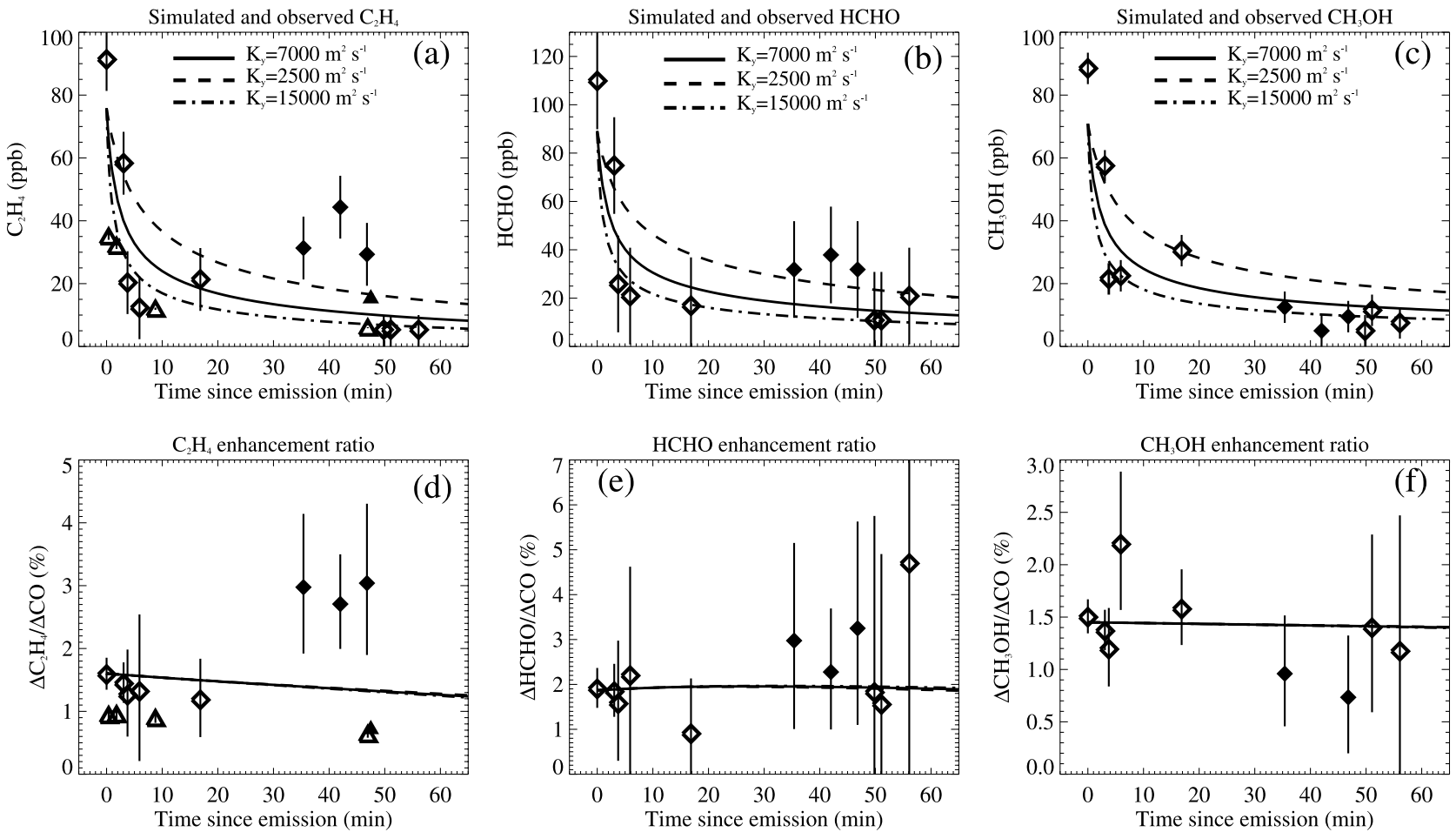

Figure 6. Measured and simulated mixing ratios $(\mathrm{a}-\mathrm{c})$ and enhancement ratios with respect to $\mathrm{CO}(\mathrm{d}-\mathrm{f})$ of $\mathrm{C}_{2} \mathrm{H}_{4}, \mathrm{HCHO}$, and $\mathrm{CH}_{3} \mathrm{OH}$ in the Timbavati plume. The lines represent model simulations using three different values of $\mathrm{K}_{y}$. AFTIR measurements are represented by diamonds, triangles represent canister samples. The solid symbols represent measurements obtained in the upper part of the plume. Horizontal error bars (not shown) are identical to those shown in Figure 2. 


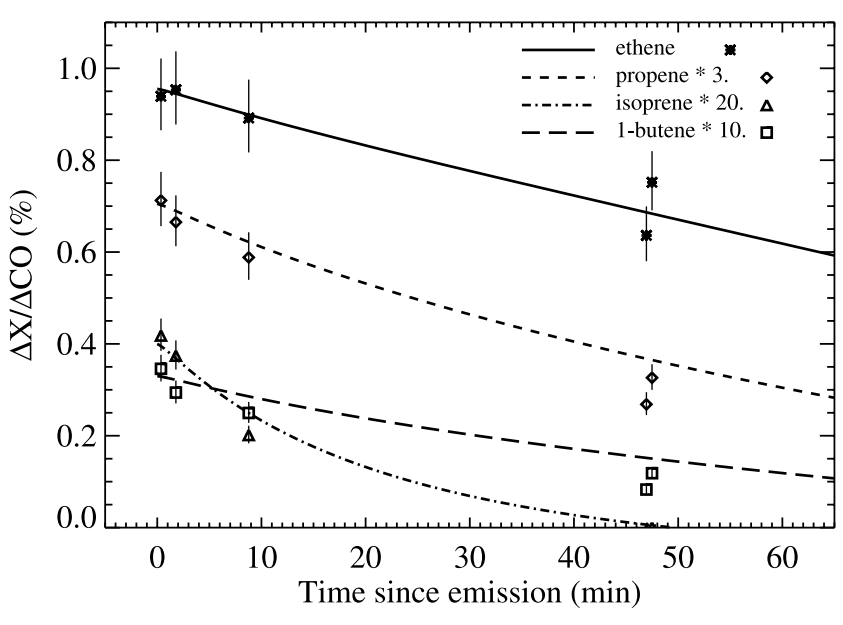

Figure 7. Measured and simulated enhancement ratios with respect to $\mathrm{CO}$ for ethene $\left(\mathrm{C}_{2} \mathrm{H}_{4}\right)$, propene, isoprene, and 1-butene along the Timbavati plume. A value of 0.645 has been subtracted from the simulated $\Delta \mathrm{C}_{2} \mathrm{H}_{4} / \Delta \mathrm{CO}$ enhancement ratio to account for differences in the measured ethene emission ratio by AFTIR and canister sampling. Horizontal error bars (not shown) are identical to those shown in Figure 2.

levels of the plume yield a slightly higher $\Delta \mathrm{HCHO} / \Delta \mathrm{CO}$ ratio than the other measurements, indicating a slightly enhanced $\mathrm{HCHO}$ emission factor for this part of the plume. However, considering the uncertainties related to the enhancement ratios, the difference is not significant. In general, the measured and the modeled $\Delta \mathrm{HCHO} / \Delta \mathrm{CO}$ ratio shows little variation, indicating that primary emissions dominated the $\mathrm{HCHO}$ mixing ratio in the plume during the first hour.

[31] The comparison between the measured and simulated mixing ratios and enhancement ratios for $\mathrm{CH}_{3} \mathrm{OH}$ reveals that the results from the model simulations are slightly higher than the measured values. This overestimation is especially pronounced for the measurements taken in the upper part of the plume (solid symbols and dashed line in Figure 6c), where the measurements lay well below $20 \mathrm{ppb}$ while the model predicts methanol levels of about $25 \mathrm{ppb}$. (Note the low detection limit and measurement uncertainty of $5 \mathrm{ppb}$ for the methanol excess mixing ratio as measured by AFTIR.) This is an indication that the photochemical sink of methanol may be underestimated in the model simulations, at least for the measurement taken in the upper part of the plume. The reaction with the $\mathrm{OH}$ radical $(8.5 \times$ $10^{-13} \mathrm{~cm}^{3}$ molecules ${ }^{-1} \mathrm{~s}^{-1}$ at $288 \mathrm{~K}$ [Jiménez et al., 2003]) is the only sink for methanol considered in the standard model simulation.

[32] The simulated average $\mathrm{OH}$ concentration in the plume is $7.7 \times 10^{6}$ molecules $\mathrm{cm}^{-3}$; lower than the value derived from the decay of hydrocarbons $\left(1.7 \times 10^{7}\right.$ molecules $\mathrm{cm}^{-3}$ ), which was based on the previous wind speed estimate [Hobbs et al., 2003]. Figure 7 presents the evolution of the measured and simulated enhancement ratio of four hydrocarbons with respect to $\mathrm{CO}$ in the Timbavati plume. All presented compounds are mainly oxidized by the $\mathrm{OH}$ radical, while $\mathrm{CO}$ can be considered chemically inert on the timescale of $1 \mathrm{~h}$. The model closely follows the observed decrease of the ethene enhancement ratio, while it slightly underestimates the decreases of propene, isoprene, and 1-butene along the plume. This suggests that the $\mathrm{OH}$ concentration might be underestimated in the model. Higher $\mathrm{OH}$ concentration in the model would lead to enhanced production of ozone. However, uncertainties in the rate coefficients of the $\mathrm{OH}$ reactions of the mentioned organic compounds might also contribute to slight differences between the model results and the measurements.

[33] Figure 8 presents the measured and simulated formic and acetic acid mixing ratios and their enhancement ratios with respect to $\mathrm{CO}$ in the Timbavati plume. The measurements show a constant $\Delta \mathrm{HCOOH} / \Delta \mathrm{CO}$ ratio downwind of the fire, while an increase in the $\Delta \mathrm{CH}_{3} \mathrm{COOH} / \Delta \mathrm{CO}$ ratio from a value of about $1.5 \%$ to about $7 \%$ is observed. The model simulations result in a constant enhancement ratio for formic and acetic acid in the smoke plume (i.e., negligible photochemical production and destruction) in contrast to the observations for acetic acid. The measured increase of the $\Delta \mathrm{CH}_{3} \mathrm{COOH} / \Delta \mathrm{CO}$ ratio suggests a modest source of gasphase acetic acid in the Timbavati plume. However, given the uncertainties in the field measurements, this trend might not be statistically significant. A similar increase has been observed in other African smoke plumes during SAFARI 2000 [Yokelson et al., 2003a] and in Alaskan smoke plumes [Goode et al., 2000]. The cause for this increase in the measured $\Delta \mathrm{CH}_{3} \mathrm{COOH} / \Delta \mathrm{CO}$ enhancement ratio is unclear; possible processes to explain this observation are explored in section 7.

[34] In a previous study of a smoke plume in Namibia during SAFARI 2000, a downwind production of acetone was found, which could not be reproduced by model simulations using an earlier version of the model we used [Jost et al., 2003]. The model has been significantly extended since then to include the emissions and the photochemistry of chemical species recently found in biomass smoke [Christian et al., 2003], but still does not predict acetone production. It is interesting to note that we do find photochemical production of glyoxal $\left((\mathrm{CHO})_{2}\right)$, mainly from the oxidation of furan, leading to a simulated glyoxal mixing ratio of about $450 \mathrm{ppt}$, equivalent to an enhancement ratio with respect to CO of $0.055 \%$. Glyoxal and acetone have the same molecular mass (58 amu), which makes them indistinguishable for methods employing mass spectrometry, such as the Atmospheric Pressure Chemical Ionization Mass Spectrometer (AP-CIMS) used by Jost et al. [2003]. Therefore it cannot be ruled out, as stated by Jost et al. [2003], that at least part of the production attributed to acetone was due to the formation of glyoxal. The magnitude of the glyoxal formation found in the present study, however, is significantly smaller than the production of mass 58 found by Jost et al. [2003]. Methylvinylether (MVE), another compound with a molecular mass of 58, is also found in smoke from biomass burning [Christian et al., 2003]. Photochemical formation of MVE has been neither observed nor simulated. Primary emissions of glyoxal were found to make no significant contribution to the emissions of mass 58 [Christian et al., 2004]. Based on the extended photochemical model used in the present study, the acetone production measured in the previous study still cannot be reproduced. This highlights the importance for a better characterization and quantification of the full suite of carbon 

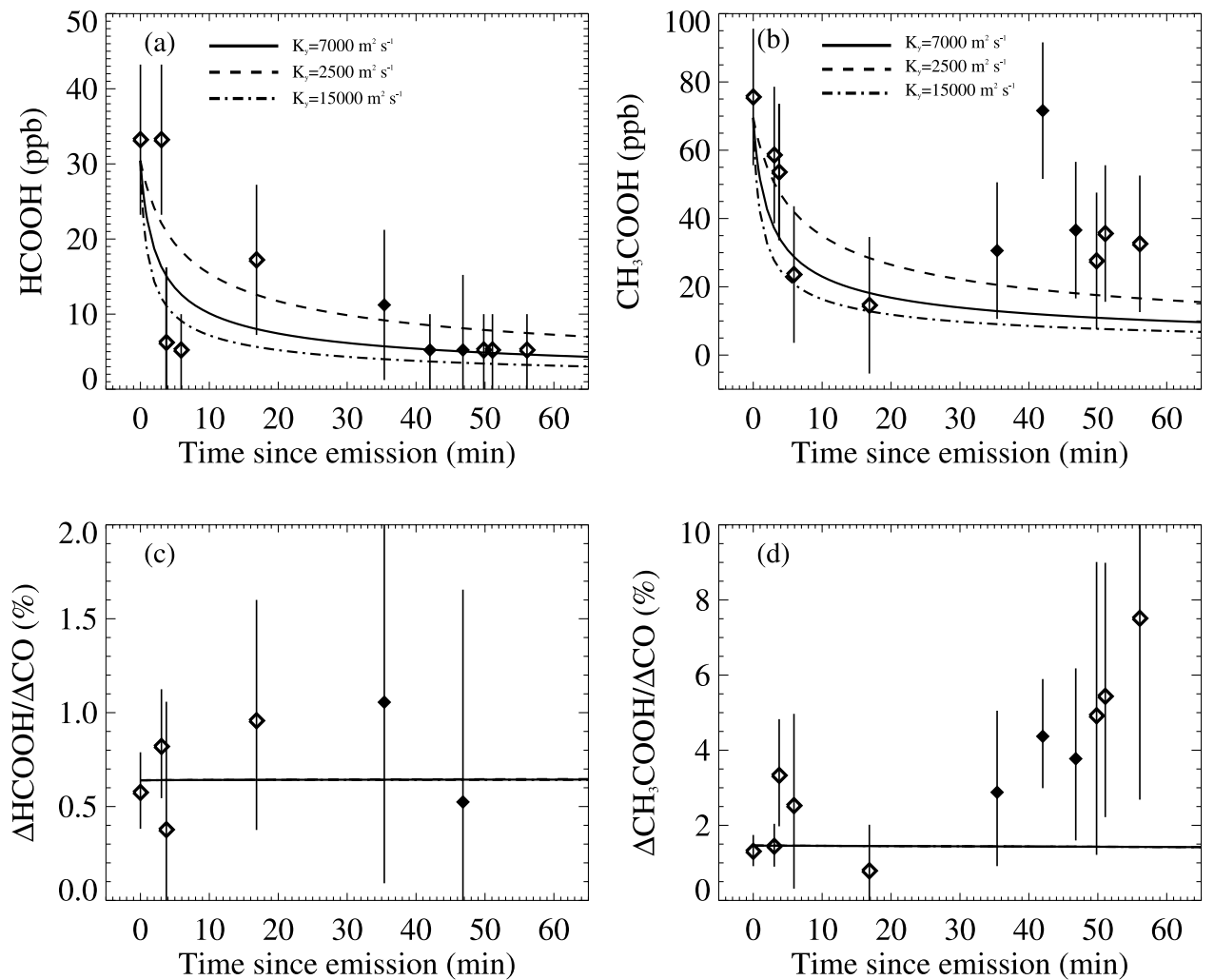

Figure 8. Measured and simulated mixing ratios (a, b), and enhancement ratios with respect to $\mathrm{CO}(\mathrm{c}, \mathrm{d})$ of $\mathrm{HCOOH}$ and $\mathrm{CH}_{3} \mathrm{COOH}$ in the Timbavati plume. The lines represent model simulations using three different values of $\mathrm{K}_{v}$. AFTIR measurements are represented by diamonds. The solid symbols represent measurements obtained in the upper part of the plume. Horizontal error bars (not shown) are identical to those shown in Figure 2.

compounds emitted by fires and their atmospheric photochemistry.

\section{Sensitivities}

[35] In this section we explore potentially important chemistry that could be added to the model to increase the agreement with the measurements.

\subsection{Impact of Smoke-Modified Photolysis Frequencies}

[36] The interaction of the smoke particles with solar radiation modifies the actinic flux available for photolytic reactions in smoke plumes. The overall effect of the smoke particles on the photolysis frequencies in the plume is sensitive to a number of factors, including aerosol optical depth, aerosol optical properties, the spatial distribution of particles, and three-dimensional effects [e.g., Dickerson et al., 1997; He and Carmichael, 1999; Jacobson, 1998; Früh et al., 2000; Trentmann et al., 2003b]. As these properties are not available to the required accuracy and they cannot be calculated within the present 0 -dimensional model approach, a detailed representation of the interaction between the smoke particles and solar radiation, and the subsequent effect on photochemistry, is not possible here. However, an estimate of the impact of the smoke particles on the photolysis rates can be deduced based on measurements of the upward- and downward-irradiance measured onboard the University of Washington's Convair 580 aircraft using the SSFR [Pilewskie et al., 2003]. We evaluated the measurements of the upward- and downward-irradiance integrated between $350 \mathrm{~nm}$ and $450 \mathrm{~nm}$ performed at the times of the AFTIR measurements. A solar radiative transfer model [Stamnes et al., 1988; Mayer and Kylling, 2005] was used to convert the irradiance into actinic flux (the radiative quantity relevant for photodissociation of atmospheric molecules [Madronich, 1987]). By comparing the retrieved values with corresponding ambient values, we conclude that a reduction of the actinic flux by $30 \%$ of the ambient value for the samples taken in the central part of the smoke plume, and an enhancement of $10 \%$ for the samples obtained in the upper part of the plume (i.e., samples e, $\mathrm{f}$, $\mathrm{g}$, and 4), are realistic approximations of the effect of the smoke particles on the photolysis frequencies in the Timbavati plume. Neglecting any potential wavelength dependence, we applied these factors to all photolysis frequencies in the model simulations. This assumption is justified for the photolysis reactions occuring in the UV/ visible range [He and Carmichael, 1999; Jacobson, 1998].

[37] Figure 9 shows the measured and the simulated ozone mixing ratios for the simulations with enhanced (to $110 \%$ of the ambient values) and reduced (to $70 \%$ of the ambient values) photolysis frequencies. Enhanced (reduced) photolysis frequencies lead to enhanced (reduced) ozone mixing ratios in the simulations. Enhancing the photolysis 

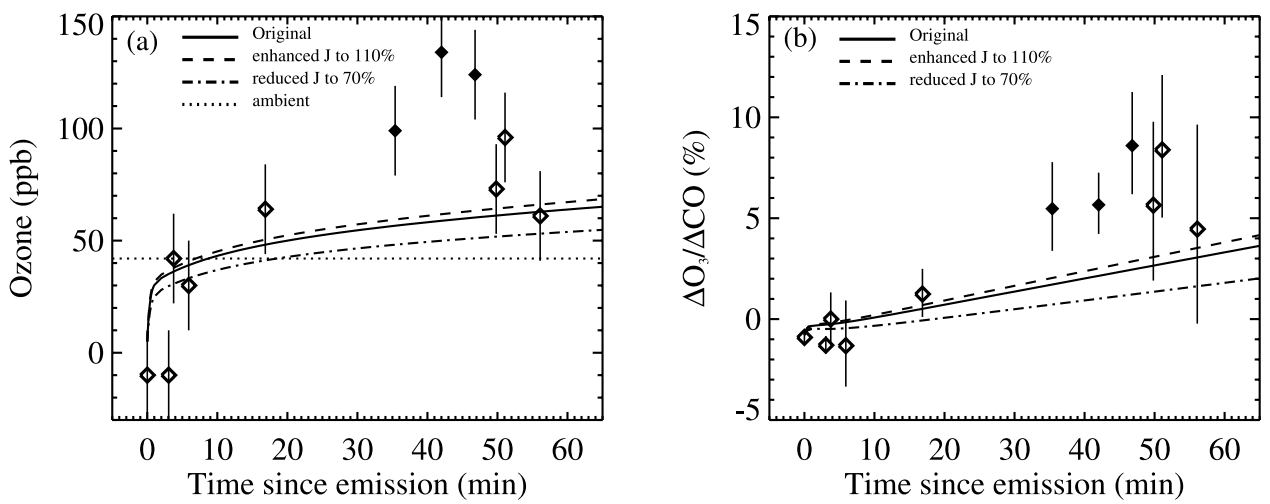

Figure 9. Measured and simulated (a) ozone mixing ratios and (b) ozone enhancement ratios with respect to $\mathrm{CO}$ in the Timbavati plume. The simulations were done without considering aerosol impacts on the photolysis frequencies (solid, black line), with enhanced photolysis frequencies (dashed line) and reduced photolysis frequencies (dashed-dotted line). AFTIR measurements are represented by diamonds. The solid symbols represent measurements obtained in the upper part of the plume. Horizontal error bars (not shown) are identical to those shown in Figure 2.

frequencies by $10 \%$ over the ambient value only slightly increases the simulated ozone concentration compared to the reference simulation under these conditions, while a $30 \%$ decrease significantly reduces the ozone mixing ratio in the model simulations. These results indicate that the reduction of the actinic flux inside the Timbavati plume had a more pronounced effect on the plume photochemistry than the enhancement in the upper part of the plume. It also suggests that there might be some shortcomings in the model simulations for the samples taken in the smoke plume since under the realistic assumption of a $30 \%$ reduction in the photolysis frequencies, the measured ozone mixing ratios cannot be reproduced by the model.

[38] We performed model simulations employing enhanced photolysis frequencies combined with less dilution $\left(\mathrm{K}_{y}=2500 \mathrm{~m}^{2} \mathrm{~s}^{-1}\right)$. Also under these conditions, the model cannot reproduce the observed high concentrations of ozone found in the samples taken in the upper parts of the plume. Therefore, we conclude that the underestimation of the simulated ozone concentration is most likely not due to the fact that we neglected the impact of the smoke aerosol on the actinic flux.

\subsection{Uncertainties in the Emissions}

[39] To assess the impact of uncertainties in the initial emission ratios on the simulated concentrations of ozone, we conducted model simulations assuming realistic uncertainties for the emission ratios. The primary goal of this study was to investigate if uncertainties in the initial emission ratios might be responsible for the underestimation of the ozone concentration in the model simulations. We note that only about $70 \%$ of the carbon emitted as VOC was identified in a recent laboratory study [Christian et al., 2003]. In addition, it is reasonable to assume that the fireaverage initial emission ratios are uncertain by $20 \%$ due to natural variability of the emissions, uncertainties in the measurements, and the use of laboratory data for some compounds. Therefore, we attribute an uncertainty of $50 \%$ to the total-VOC/CO emission ratios. Photochemical ozone production in smoke plumes is mostly sensitive to the ratio of VOC-to- $\mathrm{NO}_{x}$ emissions. To maximize the effect on the simulated ozone concentrations, we performed sensitivity studies by varying the $\mathrm{NO}_{x}$ and VOC (including HONO) emissions independently. This results in significantly larger effects on the simulated ozone mixing ratios than does the assumption of a random distribution of the uncertainties in the emission ratios of the different compounds. We therefore consider the following estimates as upper limits for the impact of uncertainties in the fire emissions on the ozone mixing ratio.

[40] Figure 10 shows the results from the reference model simulation and the model simulations employing three different combinations of enhanced and decreased emission ratios for $\mathrm{NO}_{x}$ and VOCs (including $\mathrm{HONO}$ ) by 50\% using a dilution coefficient of $\mathrm{K}_{y}=7000 \mathrm{~m}^{2} \mathrm{~s}^{-1}$. The model simulates the highest ozone mixing ratio when the emission ratios of the VOCs are enhanced and the $\mathrm{NO}_{x}$ emissions are reduced. The simulated values are significantly higher than in the reference simulation. Therefore, photochemistry occurs in the VOCs limited regime, consistent with previous findings from comparable studies of young smoke plumes [Mason et al., 2001; Trentmann et al., 2003a]. Increasing both the VOC and the $\mathrm{NO}_{x}$ emission ratios leads to a small increase in ozone compared to the reference simulation, while the simulation with simultaneously reduced VOC and $\mathrm{NO}_{x}$ emissions leads to decreased ozone concentrations in the model simulations. Reduced VOC and enhanced $\mathrm{NO}_{x}$ emissions lead to even less ozone production (not shown).

[41] To investigate whether the uncertainties in the initial emission ratios might be, at least partly, responsible for the underestimation of the ozone mixing ratio in the model simulations, we conducted model simulations using enhanced VOC and reduced $\mathrm{NO}_{x}$ emission ratios using the three different dilution scenarios. The results of these simulations are shown in Figure 11. The comparison between the simulated and the measured ozone mixing ratio and the $\Delta \mathrm{O}_{3} / \Delta \mathrm{CO}$ ratio is significantly improved compared to the reference simulation (see Figure 4). With these assumptions, the model is able to reproduce the observed ozone mixing ratios and enhancement ratios compared to 

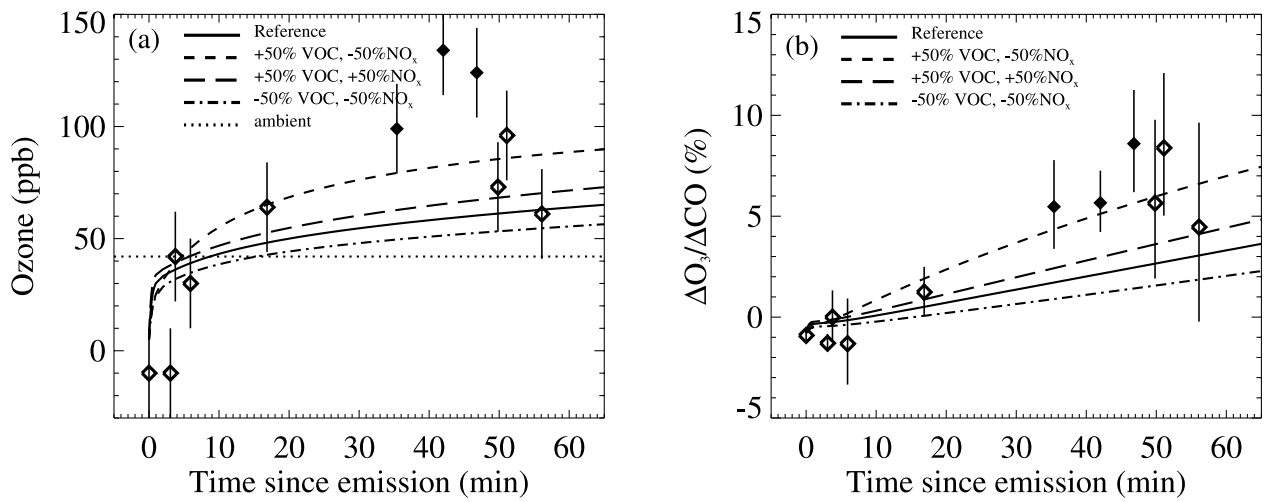

Figure 10. Measured and simulated (a) ozone mixing ratios, and (b) ozone enhancement ratios with respect to $\mathrm{CO}$ in the Timbavati plume. The simulations were conducted with increased and decreased initial emission ratios for VOCs and $\mathrm{NO}_{x}$ as indicated. AFTIR measurements are represented by diamonds. The solid symbols represent measurements obtained in the upper part of the plume. Horizontal error bars (not shown) are identical to those shown in Figure 2.

CO. However, this scenario is probably an upper limit since it requires large and coordinated changes in the emission ratios of $\mathrm{NO}_{x}$ and $\mathrm{VOC}$ to obtain a maximum effect on the simulated ozone concentration. Still, there is the possibility that much of the discrepancy between the results from the model simulations and the measurements can be explained by uncertainties in the initial emission ratios or omission of unmeasured compounds.

\subsection{Effect of Heterogeneous Reactions}

[42] Based on AFTIR measurements obtained in a smoke plume during SAFARI 2000, Yokelson et al. [2003a] found significant depletion of methanol in 5-minute old smoke that had been exposed to cloud water. Tabazadeh et al. [2004] conclude that this depletion cannot be explained by known homogeneous gas phase, heterogeneous, or aqueous phase chemistry. They attribute these observations to heterogeneous reactions occurring on the surface of cloud droplets, which are not included in standard atmospheric photochemical mechanisms. They derived estimates for the rates of the reactions of methanol with $\mathrm{OH}$ and $\mathrm{NO}_{2}$ on the surface of the cloud droplets that are consistent with the measurements.

[43] The results presented here (see section 5.3) suggest that in the Timbavati plume there was a small unexplained (i.e., not reproduced by the model simulations) reduction of methanol (see Figures 6c and 6f). The comparison between the measured and observed mixing ratio of $\mathrm{NO}_{2}$ in the Timbavati plume also suggests a potential unaccounted sink for $\mathrm{NO}_{2}$ in the model simulations (see Figure 5b). A possible increase in the $\mathrm{HCHO}$ mixing ratio due to surface reactions, as suggested by the observations and the analysis of the cloud-processed smoke [Yokelson et al., 2003a; Tabazadeh et al., 2004], is consistent with our analysis, but the difference between the model simulations and the measurements of $\mathrm{HCHO}$ for the Timbavati plume are not significant considering the uncertainties in the measurements (see Figures $6 \mathrm{~b}$ and $6 \mathrm{e}$ ).

[44] No cloud was formed in the Timbavati plume and the relative humidity was fairly low (40 to $50 \%$ ). We therefore assume that the smoke particles were covered only with a very thin film of water, if water was present at all on the
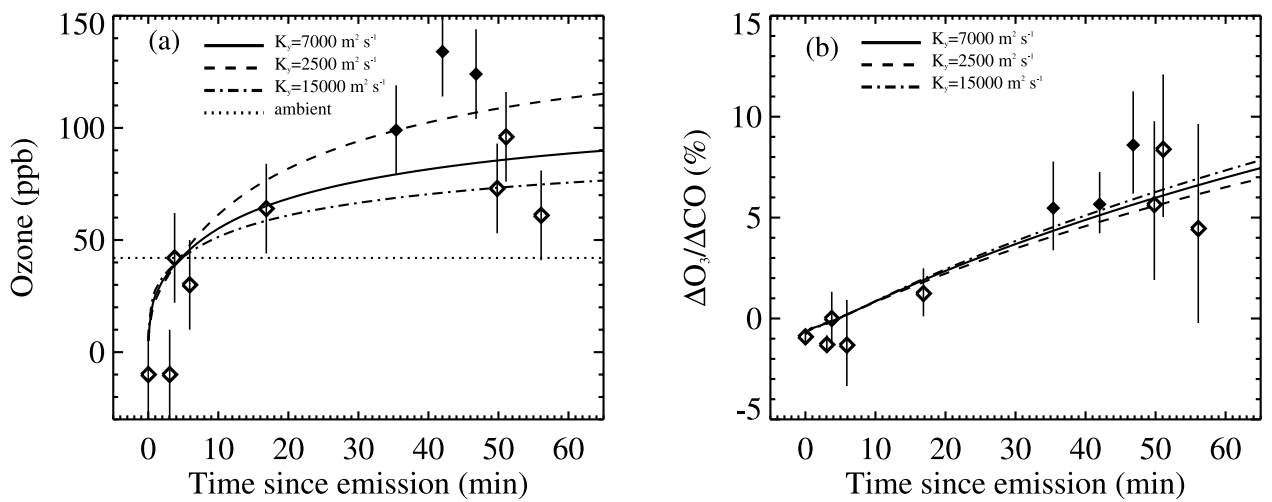

Figure 11. Measured and simulated (a) ozone mixing ratios and (b) ozone enhancement ratios with respect to $\mathrm{CO}$ in the Timbavati plume for the simulations employing enhanced VOC $(+50 \%)$ and reduced $\mathrm{NO}_{x}(-50 \%)$ emissions. The lines represent model simulations using three different values of $\mathrm{K}_{y}$. AFTIR measurements are represented by diamonds. The solid symbols represent measurements obtained in the upper part of the plume. Horizontal error bars (not shown) are identical to those shown in Figure 2. 
surface of the aerosol. Recent laboratory studies found that organic aerosol particles are liquid even under rather low relative humidities, as was the case in the Timbavati plume [e.g., Brooks et al., 2003; Parsons et al., 2004; Marcolli et al., 2004]. Humidographs taken in the Timbavati plume do not show a deliquescence point of the aerosol, also suggesting the presence of mostly liquid particles [Magi and Hobbs, 2003]. We therefore assume in the following that the proposed surface reactions occur on the surface of liquid organic smoke aerosol, which might be covered with a thin film of water. The reaction of methanol with $\mathrm{NO}_{2}$ has been found to occur on a number of surfaces [Takagi et al., 1986]. Surface reactions on atmospheric aerosol have been found to be important in the marine boundary layer [Knipping et al., 2000].

[45] To investigate the impact of the reactions of methanol on the surface of the organic smoke particles, the surface reactions of methanol with $\mathrm{OH}$ and with $\mathrm{NO}_{2}$, as proposed by Tabazadeh et al. [2004], were included in the chemical mechanism:

$$
\begin{gathered}
\mathrm{CH}_{3} \mathrm{OH}+\mathrm{OH}+\mathrm{O}_{2} \rightarrow \mathrm{HO}_{2}+\mathrm{HCHO}+\mathrm{H}_{2} \mathrm{O} \\
\mathrm{CH}_{3} \mathrm{OH}+2 \mathrm{NO}_{2}+\mathrm{O}_{2} \rightarrow \mathrm{HO}_{2}+\mathrm{HCHO}+\mathrm{HNO}_{3}+\mathrm{NO}
\end{gathered}
$$

We assume the second-order rate coefficients for (1) and (2) to be $3.68 \times 10^{-8} \mathrm{molec}^{-1} \mathrm{~cm}^{3} \mathrm{~s}^{-1} \mathrm{~cm}$ and $4.33 \times$ $10^{-13} \mathrm{molec}^{-1} \mathrm{~cm}^{3} \mathrm{~s}^{-1} \mathrm{~cm}$, respectively, corresponding to the values estimated for the reactions occurring on cloud water droplets [Tabazadeh et al., 2004].

[46] Figure 12 shows the measured and simulated mixing ratios for ozone, methanol, and $\mathrm{NO}_{2}$, together with the $\Delta \mathrm{O}_{3}$ / $\Delta \mathrm{CO}$ ratio for the reference simulation and three simulations that include the heterogeneous methanol reactions. Simulations were performed for the standard dilution scenario $\left(\mathrm{K}_{y}=7000 \mathrm{~m}^{2} \mathrm{~s}^{-1}\right)$. The inclusion of the heterogeneous reactions improves the comparison between the model results and the measurements. The model results are very sensitive to the value of the rate coefficient for the reaction of methanol with $\mathrm{NO}_{2}$. A ten-fold increase of this rate coefficient leads to significantly improved comparison between the model results and the observations for ozone, methanol, and $\mathrm{NO}_{2}$.

[47] Figure 13 presents measurements and results from model simulations employing a ten-fold increase in the reaction rate for the reaction of methanol with $\mathrm{NO}_{2}$ for the same compounds as depicted in Figure 12, and using the three values for the horizontal dilution coefficient, $\mathrm{K}_{y}$. The comparison between the model results and the measurements is much improved for all of the compounds shown. In particular, the model is now more able to simulate the low downwind concentrations of $\mathrm{NO}_{2}$ (measurements below the detection limit of $20 \mathrm{ppb}$ ) in the low dilution scenario (dashed line, compare to Figure $5 \mathrm{~b}$ ). We note that a photo-enhancement of the reaction of methanol with $\mathrm{NO}_{2}$ has been observed [Akimoto and Takagi, 1986], pointing to the possibility that this reaction was enhanced in the upper part of the plume where the measurements yielding the high ozone concentrations were performed.

[48] Based on the results presented in this section we conclude that the inclusion of the heterogeneous surface reaction between methanol and $\mathrm{NO}_{2}$ on the smoke aerosol significantly improves the comparison between the measurements and the model results. Clearly more information from laboratory studies and field observations on the proposed surface reactions is required. This study points to their potential importance for photochemistry in young smoke plumes, leading to a reduced $\mathrm{NO}_{x}$ lifetime and enhanced ozone formation.

[49] The heterogeneous reaction of methanol with $\mathrm{NO}_{2}$ leads to the formation of radicals and the reduction of $\mathrm{NO}_{x}$, both of which favor enhanced ozone production under the polluted conditions of young plumes from biomass burning. Other similar reactions might have the same overall effect on the ozone production. Reactions of $\mathrm{NO}_{2}$ with organic compounds and the subsequent production of radicals occur in the gas phase with a very low rate coefficient, making these types of reactions negligible for gas-phase atmospheric chemistry. In the aqueous phase, however, the reaction of $\mathrm{NO}_{2}$ with aromatic compounds (e.g., phenol, leading to nitrite $\left(\mathrm{NO}_{2}^{-}\right)$) has been found to take place [Alfassi et al., 1986]. Nitrite subsequently degasses to form gas phase $\mathrm{HONO}$ and $\mathrm{OH}$ radicals via photolysis of HONO. The reactions of $\mathrm{NO}_{2}$ with aromatics in liquid water have been found to be important for the production of HONO under polluted conditions [Lahoutifard et al., 2002].

[50] Considerable uncertainty exists concerning the possibility of similar reaction sequences that may occur on the surface or in the bulk of organic aerosol particles. A recent study indicates that the formation of HONO from heterogeneous $\mathrm{NO}_{2}$ reactions is enhanced by the presence of semivolatile organics on diesel soot [Gutzwiller et al., 2002], while no significant $\mathrm{HONO}$ formation from $\mathrm{NO}_{2}$ was found on the surfaces of secondary organic aerosol particles formed from the $\mathrm{OH}$ and $\mathrm{O}_{3}$ oxidation of terpenes [Bröske et al., 2003].

[51] A mechanism for the heterogeneous hydrolysis of $\mathrm{NO}_{2}$ on thin water films leading to $\mathrm{HONO}$ formation has recently been proposed [Finlayson-Pitts et al., 2003; Ramazan et al., 2004], and an additional photolytic source of HONO, possibly due to the photolysis of adsorbed nitric acid, has been observed [Zhou et al., 2002; Ramazan et al., 2004]. This reaction would also lead to an increased radical concentration and enhanced ozone production. Results from model sensitivity studies (not shown here) indicate that the uptake coefficient of the heterogeneous hydrolysis reaction of $\mathrm{NO}_{2}$ leading to $\mathrm{HONO}$ and $\mathrm{HNO}_{3}$ has to be enhanced by about three orders of magnitude, from its currently used value of $\gamma=10^{-6}$, to significantly improve the comparison between the model simulations and the measurements.

[52] Indications of heterogeneous uptake of nitrogen compounds into the particulate phase, and the potential formation of nitrite, can be derived from the analysis of the aerosol composition as a function of distance from the fire. This analysis showed an increase of nitrate $\left(\mathrm{NO}_{3}^{-}\right)$ relative to potassium $(\mathrm{K})$ with increasing distance [Gao et al., 2003; Hobbs et al., 2003]. However, according to the model results, the magnitude of this increase could be explained by the condensation of the $\mathrm{HNO}_{3}$, produced by gas-phase photochemistry. No gas-phase measurements of $\mathrm{HNO}_{3}$ are available for the Timbavati plume to determine 

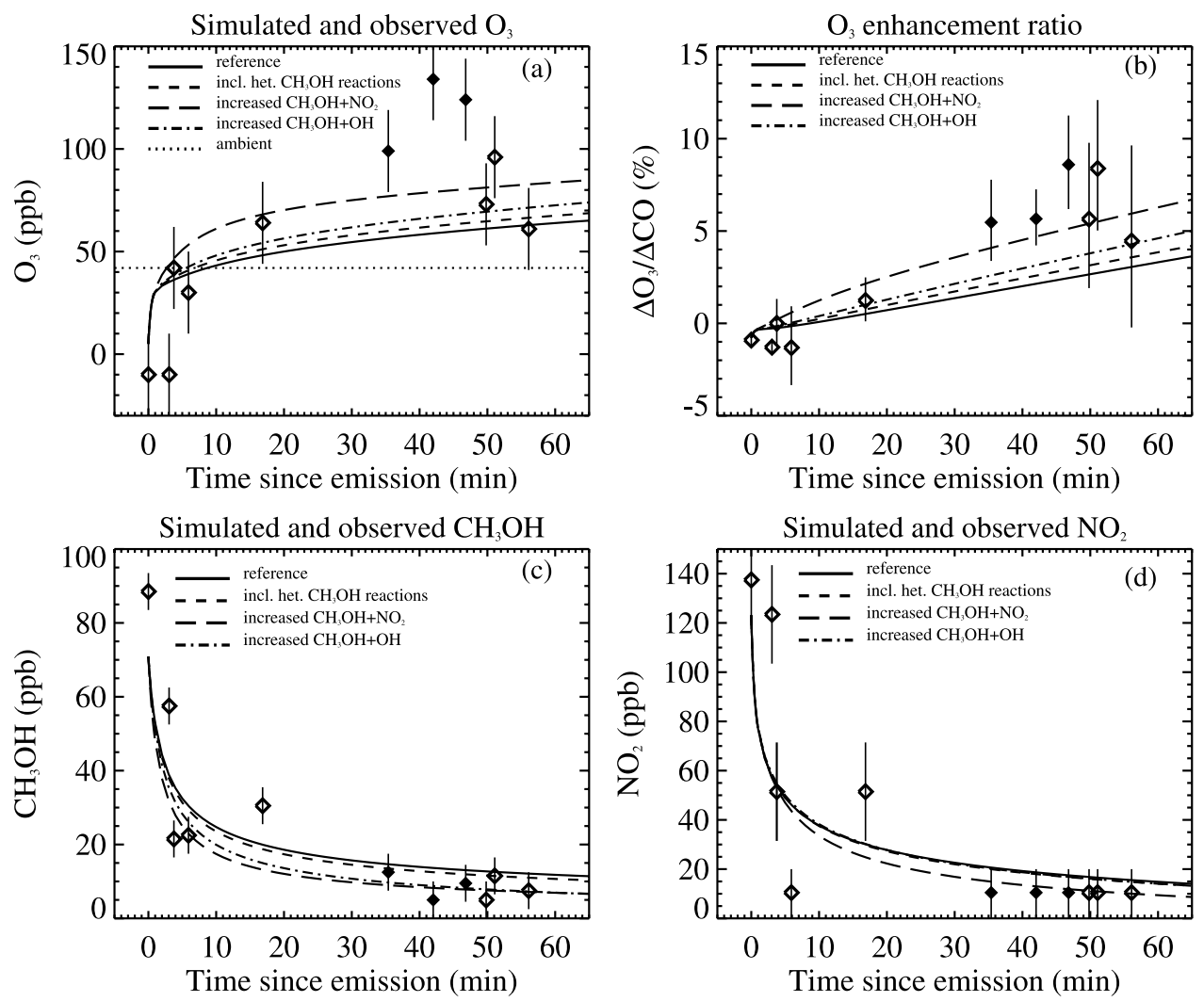

Figure 12. Measured and simulated (a) ozone mixing ratio, (b) the enhancement ratio between ozone and $\mathrm{CO}$, (c) methanol mixing ratio, and (d) nitrogen dioxide mixing ratio. Shown are results from the reference model simulations, a simulation including the two methanol surface reactions, and simulations with a ten-fold increased reaction rate for each of the proposed surface reactions. AFTIR measurements are represented by diamonds. The solid symbols represent measurements obtained in the upper part of the plume. Horizontal error bars (not shown) are identical to those shown in Figure 2.

the distribution of nitrate between the gas and the particulate phase in this smoke plume, and therefore no decisive conclusions on this issue can be drawn at this point.

[53] Not enough information is available on heterogeneous chemistry involving organic smoke aerosol at low relative humidities to include a more detailed description of the above-mentioned processes. Clearly, future research should focus on a better characterization of the phase and the composition of smoke aerosol and chemical processes occurring on the surface or in the bulk of smoke aerosol. This study shows that reactions involving $\mathrm{NO}_{2}$ and organic compounds (e.g., methanol) might play an important role in understanding chemical processes in young plumes from biomass burning and potentially in other polluted environments.

\subsection{Further Investigations}

[54] We investigated several further potential causes for the inability of the model to reproduce the observed ozone concentration using known atmospheric photochemistry.

[55] To exclude an effect of prescribed variables we conducted model simulations using different pressure, temperature, humidity, initial $\mathrm{CO}$ mixing ratio, and ambient ozone mixing ratio. None of these changes led to a significant improvement in the comparison between the model results and the measurements.
[56] To exclude potential problems with the particular numerical model used in this investigation, we conducted a model-model intercomparison with a comparable boxdilution model [Mason et al., 2001]. The latter model employs a recently updated version of the rather comprehensive NCAR Master Mechanism. In both model simulations, identical initial conditions and dilution scenarios were used. Comparison of the results from the two models for the Timbavati plume showed very good agreement for all compounds presented here [Carlson et al., 2003]. We conclude that the underestimation of the simulated ozone mixing ratio is not specific to the model used in the present study, but rather points to fundamental shortcomings in our understanding of the photochemistry in young smoke plumes.

[57] In recent laboratory experiments using African savanna fuel it was found that a significant fraction of the emitted chlorine is in the form of volatile inorganic chlorine (e.g., $\mathrm{HCl}, \mathrm{Cl}_{2}$, and $\mathrm{HOCl}$ [Keene et al., 2001]). Some of these compounds react rapidly in the troposphere with the $\mathrm{OH}$ radical or photodissociate to release atomic chlorine. In addition, filter samples taken in the Timbavati plume show that the chlorine content of the smoke aerosol relative to potassium decreases with increasing age of the smoke [Gao et al., 2003], suggesting another potential source of gasphase chlorine. Under high $\mathrm{NO}_{x}$ conditions, chlorine can 

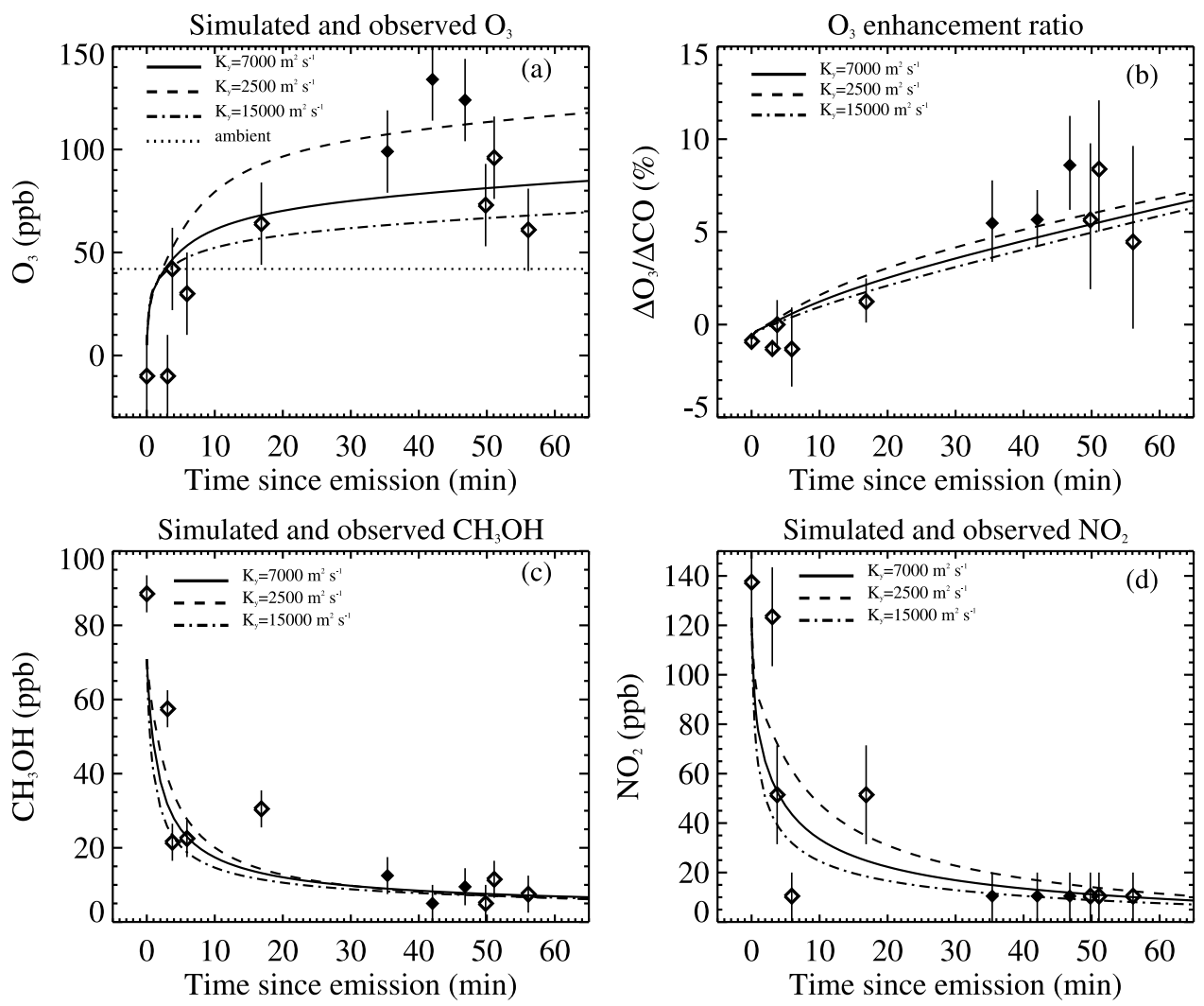

Figure 13. Measured and simulated (a) ozone mixing ratio, (b) the enhancement ratio between ozone and $\mathrm{CO}$, (c) methanol mixing ratio, and (d) nitrogen dioxide mixing ratio. The simulations were performed for the three dilution scenarios according to Figure 2, the reaction probability for the reaction $\mathrm{CH}_{3} \mathrm{OH}+\mathrm{NO}_{2}$ was enhanced by a factor of 10 compared to the estimate of Tabazadeh et al. [2004]. AFTIR measurements are represented by diamonds. The solid symbols represent measurements obtained in the upper part of the plume. Horizontal error bars (not shown) are identical to those shown in Figure 2.

lead to enhanced photochemical ozone production in polluted environments, due to additional oxidation of hydrocarbons [Knipping and Dadub, 2003; Tanaka et al., 2003]. The potential importance of oxidation of hydrocarbons by chlorine can be estimated by comparing the $\Delta \mathrm{C}_{2} \mathrm{H}_{2} / \Delta \mathrm{CO}$ enhancement ratio at different distances from the fire [Tabazadeh et al., 2004]. Because $\mathrm{C}_{2} \mathrm{H}_{2}$ is unreactive towards oxidation by $\mathrm{OH}$ but reacts fast with $\mathrm{Cl}(4.7 \times$ $10^{-11}$ molec $\left.^{-1} \mathrm{~cm}^{3} \mathrm{~s}^{-1}\right)$, a decrease in the $\Delta \mathrm{C}_{2} \mathrm{H}_{2} / \Delta \mathrm{CO}$ ratio would indicate oxidation of $\mathrm{C}_{2} \mathrm{H}_{2}$ by $\mathrm{Cl}$. However, in the case of the Timbavati plume, the $\Delta \mathrm{C}_{2} \mathrm{H}_{2} / \Delta \mathrm{CO}$ ratio remained constant over the course of one hour (see Figure $3 \mathrm{e}$ and Hobbs et al. [2003]). We therefore conclude that the levels of atomic chlorine in the gas-phase in the Timbavati plume were low, and did not contribute significantly to the oxidation of hydrocarbons and the production of ozone.

\section{Production of Acetic Acid}

[58] An increase in the $\Delta \mathrm{CH}_{3} \mathrm{COOH} / \Delta \mathrm{CO}$ enhancement ratio along the plume was observed in the Timbavati plume (Hobbs et al. [2003] and Figure 6) and in smoke plumes from other fires [Goode et al., 2000; Yokelson et al., 2003a], suggesting photochemical production of gas-phase acetic acid occurs within the first hour after the fire emissions are injected into the atmosphere. Our model simulations do not reproduce these observations. In the following, we discuss possible processes that lead to the formation of acetic acid and their potential importance for the observed increase in the $\Delta \mathrm{CH}_{3} \mathrm{COOH} / \Delta \mathrm{CO}$ ratio. Reviews of the processes determining the atmospheric abundance of short-chain organic acids, including acetic acid, can be found in Chebbi and Carlier [1996] and Khare et al. [1999].

[59] Gas-phase photochemical reactions that produce acetic acid in the model used here are the reactions of the peroxyacetyl radical $\left(\mathrm{CH}_{3} \mathrm{C}(\mathrm{O}) \mathrm{O}_{2}\right)$ with peroxyradicals, which yield acetic acid with a branching ratio of about $20 \%$ [Tyndall et al., 2001]. However, under the high $\mathrm{NO}_{x}$ conditions prevailing in smoke plumes, these reactions are only of minor importance, because the peroxyacetyl radical and the peroxyradicals almost exclusively react with NO.

[60] The ozonolysis of propene and the following reaction of the Criegee radical with water vapor is another wellestablished photochemical production pathway for acetic acid included in the model simulations. However, propene ozonolysis proceeds at a slow rate $\left(1.0 \times 10^{-17} \mathrm{molec}^{-1}\right.$ $\mathrm{cm}^{3} \mathrm{~s}^{-1}$ at $298 \mathrm{~K}$ ), and the acetic acid yield is less than $5 \%$ [Herron and Huie, 1978]. Therefore, no significant amount of acetic acid is produced via this reaction on the timescale relevant for the present study. The inclusion of the heterogeneous reactions involving methanol as discussed in section 6.3 also did not lead to any production of acetic acid. 
[61] In the following, we discuss potential processes that are not included in the model simulations, which might explain the observed formation of gas-phase acetic acid. Analogous to the formation of formic acid via the reaction of $\mathrm{HCHO}$ with $\mathrm{HO}_{2}$, the reaction of acetaldehyde with $\mathrm{HO}_{2}$ and subsequent reaction of the resulting $\mathrm{CH}_{3} \mathrm{CH}(\mathrm{OH}) \mathrm{O}_{2}$ radical with $\mathrm{NO}$ or $\mathrm{HO}_{2}$ might lead to the formation of acetic acid, as proposed by Moortgat et al. [1989]. Laboratory studies have confirmed that the initial reaction occurs at a rate comparable to the reaction between formaldehyde and $\mathrm{HO}_{2}$ [Crawford et al., 1999; Tomas et al., 2001]. The resulting hydroperoxyradical, however, is less stable and therefore less likely to undergo further reactions that could lead to the formation of acetic acid than the radical formed in the corresponding reaction of HCHO [Tomas et al., 2001]. In addition, the emission ratio of acetaldehyde $\left(\mathrm{ER}\left(\Delta \mathrm{CH}_{3} \mathrm{CHO} / \Delta \mathrm{CO}\right)=0.678 \%\right)$ based on laboratory measurements [Christian et al., 2003] is significantly smaller than the observed production of acetic acid in the field. The reaction of acetaldehyde with $\mathrm{HO}_{2}$ and subsequent reactions could therefore only explain part of the measured acetic acid production. On the other hand, substantial amounts of acetaldehyde could be emitted and be present in the particulate phase. Chemical degradation of acetaldehyde in the particulate phase might lead to the production of acetate, which can transfer into the gas-phase. The degassing of acetate as a potential source for gas-phase acetic acid will be discussed later in more detail.

[62] A recent laboratory study reports the formation of acetic acid and other organics in the reaction of ozone with a number of unsaturated hydrocarbons (Paulson et al., personal communication, 2004). Acetic acid yields of up to $10 \%$ were observed in the ozonolysis of isoprene and 2,3-dimethyl-2-butene. Currently, atmospheric photochemical models do not include these formation mechanisms for acetic acid. We note, that the $\mathrm{OH}$ reaction and the ozonolysis of 2,3-dimethyl-2-butene leads to the formation of acetone, which was found in a previous study to be photochemically produced in young smoke plumes [Jost et al., 2003]. Since the rate coefficient of the ozonolysis reaction is comparably high $\left(1.13 \times 10^{-15}\right.$ molecules ${ }^{-1} \mathrm{~cm}^{3} \mathrm{~s}^{-1}$ at 298 K) [Atkinson and Arey, 2003b], 2,3-dimethyl-2-butene has the potential to contribute to the observed acetone and acetic acid production in young plumes from biomass burning. Signals were observed at the mass associated with this compound (mass 85) in the work described by Christian et al. [2003] using a PTR-MS (R. Holzinger, private communication). The amount of the emissions observed in this laboratory study $(\Delta(\mathrm{m} 85) / \Delta(\mathrm{CO})=0.2 \%)$ is less than needed to explain the measured production of acetic acid in the Timbavati plume, but may contribute significantly to the acetone formation observed by Jost et al. [2003].

[63] Other unidentified emission compounds and their atmospheric oxidation might enable the model simulation to reproduce the measured formation of acetic acid. Potential candidates for unidentified emissions that yield acetic acid as one of their atmospheric oxidation products are methyl-, ethyl-, isopropyl-, and isobutyl-acetate [Mellouki et al., 2003]. However, their reactivity with the $\mathrm{OH}$ radical is low [Christensen et al., 2000; Picquet et al., 1998], and these compounds have not been observed as emission products from the combustion of biomass. It has been speculated that the atmospheric degradation of terpenes might lead to the formation of acetic acid [Jacob and Wofsy, 1988], and terpenes have been found in biomass smoke [Ciccioli et al., 2001]. However, high uncertainty must be attributed to these emissions and, so far, laboratory studies did not identify acetic acid as an oxidation product of terpenes [e.g., Orlando et al., 2000; Jaoui and Kamens, 2003; Atkinson and Arey, 2003a].

[64] We note that no significant formation of formic acid was simulated in our model simulation in accordance with the field measurements. The atmospheric oxidation of any potential unidentified emission compounds leading to acetic acid should therefore not produce large quantities of formic acid.

[65] Degassing of acetate from the particulate phase to form gas-phase acetic acid is another possibility to explain the presence of the enhanced mixing ratios of gas-phase acetic acid in the downwind measurements reported here. This process has been proposed to occur in the atmosphere due to the replacement of organic acids in the particulate phase with nitrate, which is produced by gas-phase photochemistry $\left(\mathrm{HNO}_{3}\right)$ [Tabazadeh et al., 1998]. In the Timbavati plume, production of particulate formate and acetate was found by relating their concentrations to the concentration of potassium, which can be assumed to be a passive tracer [Gao et al., 2003]. The $\mathrm{CH}_{3} \mathrm{COO} / \mathrm{K}$ ratio increased from a value of 0.038 for a filter sample close to the fire to a value of 0.275 in a sample taken at a distance of about $30 \mathrm{~km}$ downwind the fire (i.e. approximately 50 minutes after the emissions were injected into the atmosphere). The absolute concentration of acetate dropped from $2.7 \mu \mathrm{g} \mathrm{m}^{-3}$ to $1.1 \mathrm{\mu g} \mathrm{m}^{-3}$ between these two samples. While the increase in the $\mathrm{CH}_{3} \mathrm{COO} / \mathrm{K}$ ratio suggests production of acetate in the particulate phase, the absolute concentration of acetate present in the particles is far below the gas-phase concentration of acetic acid (gas phase: approx. $30 \mathrm{ppb}$ $\mathrm{CH}_{3} \mathrm{COOH}$, particulate phase: approx. $1 \mathrm{ppb} \mathrm{CH}_{3} \mathrm{COO}$ ). To explain the measured increase of gas-phase acetic acid, the main part of the particulate acetate would have to have degassed quickly from the particulate phase. This process is rather unlikely, but cannot be excluded. Based on the filter measurements, no compound could be identified that could serve as a source for acetate in the particles (i.e., the ratio of this compound to potassium would decrease with distance from the Timbavati fire). In a recent laboratory study, gaseous acetic acid was found as a minor product in the oxidation of pyrene surfaces by $\mathrm{OH}$ [Molina et al., 2004].

[66] Chemical reactions on the surface of the smoke particles (rather than in the bulk of the particles) would be more consistent with the observations. One possible pathway, though highly speculative, would be a catalytic pathway that produces acetic acid from methane, $\mathrm{CO}$, or methanol. Transformations of these compounds into acetic acid have been reported in the laboratory under different conditions and in the presence of different catalysts (e.g., vanadium complexes) [e.g., Nizova et al., 1998; Periana et al., 2003; Reis et al., 2003]. The chemical composition of biomass-burning particles is still rather poorly understood and depends on the fuel type, but they do contain a large number of elements, including metals that might serve as 
catalysts for the above mentioned reactions [Turn et al., 1997].

[67] We conclude that the origin of the observed production of gas-phase acetic acid found in the plume from the Timbavati fire and in other plumes from biomass burning remains uncertain. It is possible that the inclusion of a, so far, unidentified compound in the fire emission that leads to the formation of acetic acid (e.g., 2,3-dimethyl-2-butene) would also improve the model performance with regards to the ozone measurements. Further detailed measurements of fire emissions and their downwind evolution are highly desirable. Our analysis suggests that the particulate phase might be important for understanding processes in young smoke plumes and potentially in other polluted environments. Further laboratory and field studies involving the interactions between the gas and the particulate phase are needed.

\section{Summary and Conclusions}

[68] We have conducted a detailed investigation of the photochemical processes that occurred in the plume from the prescribed Timbavati savanna fire using a photochemical box-dilution model constrained to and evaluated with field measurements. The model includes representations of the atmospheric photochemical oxidation mechanisms of the main emissions from savanna fires, including toluene, phenol, and furan. Comprehensive field measurements of chemically passive tracers (e.g., CO) along the smoke plume allow constraint of the model simulations.

[69] The field measurements show a production of ozone and acetic acid within the first hour after the emissions were injected into the atmosphere. The model also simulates photochemical production of ozone, but underestimates the amount compared to the field measurements. While the observations show ozone mixing ratios up to about $140 \mathrm{ppb}$ and a $\Delta \mathrm{O}_{3} / \Delta \mathrm{CO}$ enhancement ratio of $8 \%$, the corresponding values from the model simulations are about $70 \mathrm{ppb}$ and $4 \%$, respectively. Besides underestimating the ozone production, the model results suggest an underprediction of the photochemical loss of methanol and nitrogen dioxide in the plume. Several possible reasons for the underestimation of the ozone concentration have been presented, including the potential impact of the smoke aerosol on the photolysis frequencies and uncertainties in the initial emissions. The reduction of the photolysis frequencies due to the presence of the smoke reduces the simulated ozone mixing ratio. Assuming a possible increase in the $\mathrm{VOC} / \mathrm{NO}_{x}$ emission ratio significantly improved the model-measurement comparison. The inclusion of a previously proposed surface reaction of methanol with $\mathrm{NO}_{2}$ also improves the comparison between the model results and the field measurements.

[70] No significant production of acetic acid is simulated, thus the cause for the observed increase in the $\Delta \mathrm{CH}_{3} \mathrm{COOH} /$ $\Delta \mathrm{CO}$ ratio remains unclear. Known gas-phase reactions of known emissions are not responsible for the observed production of acetic acid. Inclusion of so-far undetected emissions with properties such as those of 2,3-dimethyl-2butene might help to improve the comparison between the model results and the field measurements. So far 2,3dimethyl-2-butene has not been found in smoke from biomass burning. Processes involving the particulate phase (either on the surface or in the bulk of the particles) might also contribute to the measured production of acetic acid in the Timbavati plume.

[71] The present study used the most comprehensive data set to date on chemical transformations in young plumes from biomass burning to investigate the processes that lead to the observed increases in ozone and acetic acid. The remaining discrepancies between the results from the model simulations and the field observations point to significant shortcomings in our understanding of young smoke plumes. In particular, speciating the unidentified VOCs and characterizing gas-particle interactions deserve more attention.

[72] Acknowledgments. J.T. thanks the Alexander von Humboldt Foundation for support through a Feodor-Lynen fellowship. We thank Brian Magi, Parikhit 'Ricky' Sinha, and Art Rangno for help in collecting data and numerous helpful discussions; Peter Pilewskie and John Pommier for providing the radiation data; Don Blake and his group at UCI for analyzing the canister data; Lyatt Jaeglé and Rolf von Kuhlmann for supplying the global model data and helpful discussions; Boris Bonn for providing the MEK oxidation mechanism; Suzanne Paulson for unpublished data and helpful discussions; Song Gao and Dean Hegg for providing the filter data and helpful discussions; Adrian Sandu for making KPP and Bernhard Mayer and Arve Kylling for making libRadtran publicly available. We thank the reviewers for their helpful comments.

\section{References}

Akimoto, H., and H. Takagi (1986), Formation of methyl nitrite in the surface reaction of nitrogen dioxide and methanol. 2. Photoenhancement, Environ. Sci. Technol., 20(4), 393-397.

Alfassi, Z. B., R. E. Huie, and P. Neta (1986), Substituent effects on rates of one-electron oxidation of phenols by the radicals $\mathrm{ClO}_{2}, \mathrm{NO}_{2}$, and $\mathrm{SO}_{3}^{-}$, J. Phys. Chem., 90, 4156-4158.

Anderson, B. E., et al. (1996), Aerosols from biomass burning over the tropical South Atlantic region: Distribution and impacts, J. Geophys. Res., 101(D19), 24,117-24,137.

Andreae, M. O., and P. Merlet (2001), Emission of trace gases and aerosols from biomass burning, Global Biogeochem. Cycles, 15(4), 955-966.

Andreae, M. O., E. Atlas, H. Cachier, W. R. Cofer, G. W. Harris, G. Helas, R. Koppmann, J.-P. Lacaux, and D. Ward (1996a), Trace gas and aerosol emissions from savanna fires, in Biomass Burning and Global Change, edited by J. S. Levine, pp. 278-295, MIT Press, Cambridge, Mass.

Andreae, M. O., J. Fishman, and J. Lindesay (1996b), The Southern Tropical Atlantic Region Experiment (STARE): Transport and Atmospheric Chemistry near the Equator-Atlantic (TRACE A) and Southern African Fire-Atmosphere Research Initiative (SAFARI): An introduction, J. Geophys. Res., 101(D19), 23,519-23,520.

Andreae, M. O., D. Rosenfeld, P. Artaxo, A. A. Costa, G. P. Frank, K. M. Longo, and M. A. F. Silva-Dias (2004), Smoking rain clouds over the Amazon, Science, 303, 1337-1342.

Artaxo, P., F. Gerab, M. A. Yamasoe, and J. V. Martins (1994), Fine mode aerosol composition at three long-term atmospheric monitoring sites in the Amazon Basin, J. Geophys. Res., 99(D11), 22,857-22,868.

Atkinson, R., and J. Arey (2003a), Gas-phase tropospheric chemistry of biogenic volatile organic compounds: a review, Atmos. Environ., 37, suppl. 2, S197-S219.

Atkinson, R., and J. Arey (2003b), Atmospheric degradation of volatile organic compounds, Chem. Rev., 103, 4605-4638.

Atkinson, R., D. L. Baulch, R. A. Cox, R. F. Hampson Jr., J. A. Kerr, M. J. Rossi, and J. Troe (1997), Evaluated kinetic and photochemical data for atmospheric chemistry, Supplement V, J. Phys. Chem. Ref. Data, 26(3), $521-1011$.

Atkinson, R., D. L. Baulch, R. A. Cox, J. N. Crowley, R. F. Hampson Jr., M. E. Jenkin, J. A. Kerr, M. J. Rossi, and J. Troe (2004), Summary of evaluated kinetic and photochemical data for atmospheric chemistry Web version July 2004, Cambridge Univ., Cambridge, UK. (Available at http://www.iupac-kinetic.ch.cam.ac.uk/)

Berndt, T., and O. Böge (2003), Gas-phase reaction of $\mathrm{OH}$ radicals with phenol, Phys. Chem. Chem. Phys., 5, 342-350.

Bey, I., et al. (2001), Global modeling of tropospheric chemistry with assimilated meteorology: Model description and evaluation, J. Geophys. Res., 106(D19), 23,073-23,095.

Bonn, B., R. von Kuhlmann, and M. G. Lawrence (2004), High contribution of biogenic hydroperoxides to secondary organic aerosol formation, Geophys. Res. Lett., 31, L10108, doi:10.1029/2003GL019172. 
Bremer, H., et al. (2004), Spatial and temporal variation of MOPITT CO in Africa and South America: A comparison with SHADOZ ozone and MODIS aerosol, J. Geophys. Res., 109, D12304, doi:10.1029/ 2003JD004234

Brooks, S. D., R. M. Garland, M. E. Wise, A. J. Prenni, M. Cushing, E. Hewitt, and M. A. Tolbert (2003), Phase changes in internally mixed maleic acid/ammonium sulfate aerosols, J. Geophys. Res., 108(D15), 4487, doi:10.1029/2002JD003204.

Bröske, R., J. Kleffmann, and P. Wiesen (2003), Heterogeneous conversion of $\mathrm{NO}_{2}$ on secondary organic aerosol surfaces: A possible source of nitrous acid (HONO) in the atmosphere?, Atmos. Chem. Phys., 3, $469-474$.

Butkovskaya, N. I., A. Kukui, N. Pouvesle, and G. Le Bras (2004), Rate constant and mechanism of the reaction of $\mathrm{OH}$ radicals with acetic acid in the temperature range of 229-300 K, J. Phys. Chem. A, 108(34), $7021-$ 7026.

Calvé, S. L., G. L. Bras, and A. Mellouki (1997), Temperature dependence for the rate coefficients of the reactions of the $\mathrm{OH}$ radical with a series of formates, J. Phys. Chem. A, 101, 5489-5493.

Calvert, J. G., R. Atkinson, K. H. Becker, R. M. Kamens, J. H. Seinfeld, T. J. Wallington, and G. Yarwood (2001), The Mechanisms of Atmospheric Oxidation of Aromatic Hydrocarbons, Oxford University Press.

Carlson, L. J., S. A. Mason, J. Trentmann, P. V. Hobbs, T. Winterrath, M. O Andreae, T. J. Christian, and R. J. Yokelson (2003), Comparison of biomass burning smoke plume models, paper presented at AGU Fall Meeting, San Francisco, Calif.

Chatfield, R. B., and A. C. Delany (1990), Convection links biomass burning to increased tropical ozone: However, models will tend to overpredict $\mathrm{O}_{3}, J$. Geophys. Res., 95(D11), 18,473-18,488.

Chatfield, R. B., J. A. Vastano, L. Li, G. W. Sachse, and V. S. Connors (1998), The Great African plume from biomass burning: Generalizations from a three-dimensional study of TRACE A carbon monoxide, J. Geophys. Res., 103(D21), 28,059-28,077.

Chebbi, A., and P. Carlier (1996), Carboxylic acids in the troposphere, occurrence, sources, and sinks: A review, Atmos. Environ., 30(24), $4233-4249$

Christensen, L. K., J. C. Ball, and T. J. Wallington (2000), Atmospheric oxidation mechanism of methyl acetate, J. Phys. Chem. A, 104(2), 345351.

Christian, T. J., B. Kleiss, R. J. Yokelson, R. Holzinger, P. J. Crutzen, W. M Hao, B. H. Saharjo, and D. E. Ward (2003), Comprehensive laboratory measurements of biomass-burning emissions: 1. Emissions from Indonesian, African, and other fuels, J. Geophys. Res., 108(D23), 4719 doi:10.1029/2003JD003704.

Christian, T. J., B. Kleiss, R. J. Yokelson, R. Holzinger, P. J. Crutzen, W. M Hao, T. Shirai, and D. R. Blake (2004), Comprehensive laboratory measurements of biomass-burning emissions: 2. First intercomparison of open-path FTIR, PTR-MS, and GC-MS/FID/ECD, J. Geophys. Res., 109, D02311, doi:10.1029/2003JD003874.

Ciccioli, P., E. Brancaleoni, M. Frattoni, A. Cecinato, and L. Pinciarell (2001), Determination of volatile organic compounds (VOC) emitted from biomass burning of mediterranean vegetation species by GC-MS Anal. Lett., 34(6), 937-955.

Colman, J. J., A. L. Swanson, S. Meinardi, B. C. Sive, D. R. Blake, and F. S. Rowland (2001), Description of the analysis of a wide range of volatile organic compounds in whole air samples collected during PEMTropics A and B, Anal. Chem., 73, 3723-3731.

Crawford, M. A., T. J. Wallington, J. J. Szente, M. M. Maricq, and J. S Francisco (1999), Kinetics and mechanism of the Acetylperoxy $+\mathrm{HO}_{2}$ reaction, J. Phys. Chem. A, 103(3), 365-378.

Crutzen, P. J., and M. O. Andreae (1990), Biomass burning in the tropics: Impact on atmospheric chemistry and biogeochemical cycles, Science, $250,1669-1678$

Damian, V., A. Sandu, M. Damian, F. Potra, and G. R. Carmichael (2002), The Kinetic PreProcessor KPP - A software environment for solving chemical kinetics, Computers and Chem. Eng., 26(11), 1567-1579.

Delmas, R. A., et al. (1999), Experiment for regional sources and sinks of oxidants (EXPRESSO): An overview, J. Geophys. Res., 104(D23), 30,609-30,624

Dickerson, R. R., S. Kondragunta, G. Stenchikov, K. L. Civerolo, B. G. Doddridge, and B. N. Holben (1997), The impact of aerosols on solar ultraviolet radiation and photochemical smog, Science, 278 $827-830$

Duncan, B. N., I. Bey, M. Chin, L. J. Mickley, T. D. Fairlie, R. V. Martin, and H. Matsueda (2003a), Indonesian wildfires of 1997: Impact on tropospheric chemistry, J. Geophys. Res., 108(D15), 4458, doi:10.1029/ 2002JD003195.

Duncan, B. N., R. V. Martin, A. C. Staudt, R. Yevich, and J. A. Logan (2003b), Interannual and seasonal variability of biomass burning emis- sions constrained by satellite observations, J. Geophys. Res., 108(D2), 4100, doi:10.1029/2002JD002378.

Dunlea, E. J., and A. R. Ravishankara (2004a), Kinetic studies of the reactions of $\mathrm{O}\left({ }^{1} \mathrm{D}\right)$ with several atmospheric molecules, Phys. Chem. Chem. Phys., 6, 2152-2161.

Dunlea, E. J., and A. R. Ravishankara (2004b), Measurements of the rate coefficient for the reaction of $\mathrm{O}\left({ }^{1} \mathrm{D}\right)$ with $\mathrm{H}_{2} \mathrm{O}$ and re-evaluation of the atmospheric $\mathrm{OH}$ production rate, Phys. Chem. Chem. Phys., 6, $3333-$ 3340 .

Dwyer, E., S. Pinock, J.-M. Grégoire, and J. M. C. Pereira (2000), Global spatial and temporal distribution of vegetation fire as determined from satellite observations, Int. J. Remote Sensing, 21(6\&7), 1289-1302.

Evans, L. F., N. K. King, D. R. Packham, and E. T. Stephens (1974), Ozone measurements in smoke from forest fires, Environ. Sci. Technol., 8(1), $75-76$.

Evans, L. F., I. A. Weeks, A. J. Eccleston, and D. R. Packham (1977), Photochemical ozone in smoke from prescribed burning of forests, Environ. Sci. Technol., 11(9), 896-900.

Finlayson-Pitts, B. J., L. M. Wingen, A. L. Sumner, D. Syomin, and K. A. Ramazan (2003), The heterogeneous hydrolysis of $\mathrm{NO}_{2}$ in laboratory systems and in outdoor and indoor atmospheres: An integrated mechanism, Phys. Chem. Chem. Phys., 5, 223-242.

Fishman, J., K. Fakhruzzaman, B. Cros, and D. Nganga (1991), Identification of widespread pollution in the Southern Hemisphere deduced from satellite analyses, Science, 252, 1693-1696.

Fishman, J., A. E. Wozniak, and J. K. Creilson (2003), Global distribution of tropospheric ozone from satellite measurements using the empirically corrected tropospheric ozone residual technique: Identification of the regional aspects of air pollution, Atmos. Chem. Phys., 3, $893-907$.

Früh, B., T. Trautmann, M. Wendisch, and A. Keil (2000), Comparison of observed and simulated $\mathrm{NO}_{2}$ photodissociation frequencies in a cloudless atmosphere and in continental boundary layer clouds, J. Geophys. Res., 105(D8), 9843-9857.

Gao, S., D. A. Hegg, P. V. Hobbs, T. W. Kirchstetter, B. I. Magi, and M. Sadilek (2003), Water-soluble organic components in aerosols associated with savanna fires in southern Africa: Identification, evolution, and distribution, J. Geophys. Res., 108(D13), 8491, doi:10.1029/ 2002JD002324

Gierczak, T., M. K. Gilles, S. Bauerle, and A. R. Ravishankara (2003), Reaction of hydroxyl radical with acetone. 1. Kinetics of the reactions of $\mathrm{OH}, \mathrm{OD}$, and ${ }^{18} \mathrm{OH}$ with acetone and acetone- $d_{6}, J$. Phys. Chem. A, 107(25), 5014-5020

Good, D. A., J. Hanson, J. S. Francisco, Z. Li, and G.-R. Jeong (1999), Kinetics and reaction mechanism of hydroxyl radical reaction with methyl formate, J. Phys. Chem. A, 103(50), 10,893-10,898.

Goode, J. G., R. J. Yokelson, D. E. Ward, R. A. Susott, R. E. Babbitt, M. A. Davis, and W. M. Hao (2000), Measurements of excess $\mathrm{O}_{3}, \mathrm{CO}_{2}, \mathrm{CO}$, $\mathrm{CH}_{4}, \mathrm{C}_{2} \mathrm{H}_{4}, \mathrm{C}_{2} \mathrm{H}_{2}, \mathrm{HCN}, \mathrm{NO}, \mathrm{NH}_{3}, \mathrm{HCOOH}, \mathrm{CH}_{3} \mathrm{COOH}, \mathrm{HCHO}$, and $\mathrm{CH}_{3} \mathrm{OH}$ in 1997 Alaskan biomass burning plumes by airborne Fourier transform infrared spectroscopy (AFTIR), J. Geophys. Res., 105(D17), $22,147-22,166$

Grosjean, D., and E. L. Williams II (1992), Environmental persistence of organic compounds estimated from structure-reactivity and linear freeenergy relationships. Unsaturated aliphatics, Atmos. Environ., 26(8), $1395-1405$

Gutzwiller, L., F. Arens, U. Baltensperger, H. W. Gäggeler, and M. Ammann (2002), Significance of semivolatile diesel exhaust organics for secondary HONO formation, Environ. Sci. Technol., 36, 677-682.

Hauglustaine, D. A , and D. H. Ehhalt (2002), A three-dimensional model of molecular hydrogen in the troposphere, J. Geophys. Res., 107(D17), 4330, doi:10.1029/2001JD001156.

Haywood, J. M., S. R. Osborne, P. N. Francis, A. Keil, P. Formenti, M. O. Andreae, and P. H. Kaye (2003), The mean physical and optical properties of regional haze dominated by biomass burning aerosol measured by the C-130 aircraft during SAFARI-2000, J. Geophys. Res., 108(D13), 8473, doi:10.1029/2002JD002226.

He, S., and G. R. Carmichael (1999), Sensitivity of photolysis rates and ozone production in the troposphere to aerosol properties, J. Geophys. Res., 104(D21), 26,307-26,324.

Herron, J. T., and R. E. Huie (1978), Stopped-flow studies of the mechanisms of ozone-alkene reactions in the gas phase: Propene and isobutene, Int. J. Chem. Kinet., 10, 1019-1041.

Hobbs, P. V., J. S. Reid, J. A. Herring, J. D. Nance, R. E. Weiss, J. L. Ross, D. A. Hegg, R. D. Ottmar, and C. Liousse (1996), Particle and trace-gas measurements in the smoke from prescribed burns of forest products in the Pacific Northwest, in Biomass Burning and Global Change, edited by J. S. Levine, pp. 697-715, MIT Press, Cambridge, Mass.

Hobbs, P. V., P. Sinha, R. J. Yokelson, T. J. Christian, D. R. Blake, S. Gao, T. W. Kirchstetter, T. Novakov, and P. Pilewskie (2003), Evolution of 
gases and particles from a savanna fire in South Africa, J. Geophys. Res., 108(D13), 8485, doi:10.1029/2002JD002352.

Jacob, D. J. (2000), Heterogeneous chemistry and tropospheric ozone, Atmos. Environ., 34, $2131-2159$.

Jacob, D. J., and S. C. Wofsy (1988), Photochemistry of biogenic emissions over the Amazon forest, J. Geophys. Res., 93(D2), 1477-1486.

Jacob, D. J., et al. (1992), Summertime photochemistry of the troposphere at high northern latitudes, J. Geophys. Res., 97(D15), 16,421-16,431.

Jacobson, M. Z. (1998), Studying the effect of aerosols on vertical photolysis rate coefficient and temperature profiles over an urban airshed, J. Geophys. Res., 103(D9), 10,593-10,604.

Jaoui, M., and R. M. Kamens (2003), Gaseous and particulate oxidation products analysis of a mixture of $\alpha$-pinene $+\beta$-pinene $/ \mathrm{O}_{3} /$ air in the $\mathrm{ab}$ sence of light and $\alpha$-pinene $+\beta$-pinene/ $\mathrm{NO}_{x} /$ air in the presence of natural sunlight, J. Atmos. Chem., 44, 259-297.

Jiménez, E., M. K. Gilles, and A. R. Ravishankara (2003), Kinetics of the reactions of the hydroxyl radical with $\mathrm{CH}_{3} \mathrm{OH}$ and $\mathrm{C}_{2} \mathrm{H}_{5} \mathrm{OH}$ between 235 and $360 \mathrm{~K}, J$. Photochem. Photobiol., A: Chem., 157, $237-245$.

Jost, C., J. Trentmann, D. Sprung, M. O. Andreae, J. B. McQuaid, and H. Barjat (2003), Trace gas chemistry in a young biomass burning plume over Namibia: Observations and model simulations, J. Geophys. Res. 108(D13), 8482, doi:10.1029/2002JD002431

Kaufman, Y. J., et al. (1998), Smoke, Clouds, and Radiation-Brazil (SCAR-B) experiment, J. Geophys. Res., 103(D24), 31,783-31,808.

Keene, W. C., J. M. Lobert, J. R. Maben, D. H. Scharffe, and P. J. Crutzen (2001), Emissions of volatile inorganic halogens, carboxylic acids, $\mathrm{NH}_{3}$, and $\mathrm{SO}_{2}$ from experimental burns of southern African biofuels, paper presented at AGU Fall Meeting, San Francisco, Calif.

Khare, P., N. Kumar, K. M. Kumari, and S. S. Srivastava (1999), Atmospheric formic and acetic acids: An overview, Rev. Geophys., 37(2), $227-248$.

Kirkman, G. A., S. J. Picketh, M. O. Andreae, H. J. Annegarn, and G. Helas (2000), Distribution of aerosols, ozone and carbon monoxide over southern Africa, S. Afr. J. Sci., 96, 423-431.

Klotz, B., I. Barnes, and T. Imamura (2004), Product study of the gas-phase reactions of $\mathrm{O}_{3}, \mathrm{OH}$ and $\mathrm{NO}_{3}$ radicals with methyl vinyl ether, Phys. Chem. Chem. Phys., 6, 1725-1734.

Knipping, E. M., and D. Dadub (2003), Impact of chlorine emissions from sea-salt aerosol on coastal urban ozone, Environ. Sci. Technol., 37(2), $275-284$.

Knipping, E. M., M. J. Lakin, K. L. Foster, P. Jungwirth, D. J. Tobias, R. B Gerber, D. Dabdub, and B. J. Finlayson-Pitts (2000), Experiments and simulations of ion-enhanced interfacial chemistry on aqueous $\mathrm{NaCl}$ aerosols, Science, 288, 301-306.

Kondo, Y., et al. (2004), Impacts of biomass burning in Southeast Asia on ozone and reactive nitrogen over the western Pacific in spring, J. Geophys. Res., 109, D15S12, doi:10.1029/2003JD004203.

Lahoutifard, N., M. Ammann, L. Gutzwiller, B. Ervens, and C. George (2002), The impact of multiphase reactions of $\mathrm{NO}_{2}$ with aromatics: a modelling approach, Atmos. Chem. Phys., 2, 215-226.

Landgraf, J., and P. Crutzen (1998), An efficient method for online calculations of photolysis and heating rates, J. Atmos. Sci., 55, $863-$ 878

Lelieveld, J., and F. J. Dentener (2000), What controls tropospheric ozone?, J. Geophys. Res., 105(D3), 3531-3551.

Li, J., M. Pósfai, P. V. Hobbs, and P. R. Buseck (2003), Individual aerosol particles from biomass burning in southern Africa: 2, Compositions and aging of inorganic particles, J. Geophys. Res., 108(D13), 8484, doi:10.1029/2002JD002310.

Liousse, C., C. Devaux, F. Dulac, and H. Cachier (1995), Aging of savanna biomass burning aerosols: Consequences on their optical properties, J. Atmos. Chem., 22, 1-17.

Madronich, S. (1987), Photodissociation in the atmosphere: 1. Actinic flux and effects of ground reflections and clouds, J. Geophys. Res., 92, 9740 9752.

Magi, B., and P. V. Hobbs (2003), Effects of humidity on aerosols in southern Africa during the biomass burning season, J. Geophys. Res., 108(D13), 8495, doi:10.1029/2002JD002144

Marcolli, C., B. Luo, and T. Peter (2004), Mixing of the organic aerosol fractions: Liquids as the thermodynamically stable phases, J. Phys. Chem. A, 108(12), 2216-2224.

Marufu, L., F. Dentener, J. Lelieveld, M. O. Andreae, and G. Helas (2000), Photochemistry of the African troposphere: Influence of biomass-burning emissions, J. Geophys. Res., 105(D11), 14,513-14,530.

Mason, S. A., R. F. Field, R. J. Yokelson, M. A. Kochivar, M. R. Tinsley, D. E. Ward, and W. M. Hao (2001), Complex effects arising in smoke plume simulations due to inclusion of direct emissions of oxygenated organic species from biomass combustion, J. Geophys. Res., 106(D12), $12,527-12,539$
Mauzerall, D. L., et al. (1998), Photochemistry in biomass burning plumes and implications for tropospheric ozone over the tropical South Atlantic, J. Geophys. Res., 103(D7), 8401-8423.

Mayer, B., and A. Kylling (2005), Technical note: The libRadtran software package for radiative transfer calculations - description and examples of use, Atmos. Chem. Phys. Discuss., 5, 1319-1381.

McCabe, D. C., T. Gierczak, R. K. Talukdar, and A. R. Ravishankara (2001), Kinetics of the reaction $\mathrm{OH}+\mathrm{CO}$ under atmospheric conditions, Geophys. Res. Lett., 28(16), 3135-3138.

Mellouki, A., G. Le Bras, and H. Sidebottom (2003), Kinetics and mechanisms of the oxidation of oxygenated organic compounds in the gas phase, Chem. Rev., 103, 5077-5096.

Molina, M. J., A. V. Ivanov, S. Trakhtenberg, and L. T. Molina (2004), Atmospheric evolution of organic aerosol, Geophys. Res. Lett., 31, L22104, doi:10.1029/2004GL020910.

Moortgat, G. K., R. A. Cox, G. Schuster, J. P. Burrows, and G. S. Tyndall (1989), Peroxy radical reactions in the photo-oxidation of $\mathrm{CH}_{3} \mathrm{CHO}$, J. Chem. Soc., Faraday Trans. 2, 85(7), 809-829.

Nizova, G. V., G. Süss-Fink, S. Stanislas, and G. B. Shul'pin (1998), Carboxylation of methane with $\mathrm{CO}$ or $\mathrm{CO}_{2}$ in aqueous solution catalysed by vanadium complexes, Chem. Commun., 1885-1886.

Olariu, R. I., I. Barnes, K. H. Becker, and B. Klotz (2000), Rate coefficients for the gas-phase reaction of $\mathrm{OH}$ radicals with selected dihydroxybenzenes and benzoquinones, Int. J. Chem. Kinet., 32(11), 696-702.

Olariu, R. I., B. Klotz, I. Barnes, K. H. Becker, and R. Mocanu (2002), FT-IR study of the ring-retaining products from the reaction of $\mathrm{OH}$ radicals with phenol, $\mathrm{O}_{-}, \mathrm{m-}$, and $p$-cresol, Atmos. Environ., 36, $3685-3697$

Orlando, J. J., B. Nozière, G. S. Tyndall, G. E. Orzechowska, S. E. Paulson, and Y. Rudich (2000), Product studies of the $\mathrm{OH}$ - and ozone-initiated oxidation of some monoterpenes, J. Geophys. Res., 105(D9), 11,56111,572 .

Parsons, M. T., J. Mak, S. R. Lipetz, and A. K. Bertram (2004), Deliquescence of malonic, succinic, glutaric, and adipic acid particles, J. Geophys. Res., 109, D06212, doi:10.1029/2003JD004075.

Periana, R. A., O. Mironov, D. Taube, G. Bhalla, and C. Jones (2003) Catalytic, oxidative condensation of $\mathrm{CH}_{4}$ to $\mathrm{CH}_{3} \mathrm{COOH}$ in one step via $\mathrm{CH}$ activation, Science, 301, 814-818.

Peters, W., M. Krol, F. Dentener, A. Thompson, and J. Lelieveld (2002), Chemistry-transport modeling of the satellite observed distribution of tropical tropospheric ozone, Atmos. Chem. Phys., 2, 103-120.

Picquet, B., S. Heroux, A. Chebbi, J.-F. Doussin, R. Durand-Jolibois, A. Monod, H. Loirat, and P. Carlier (1998), Kinetics of the reactions of $\mathrm{OH}$ radicals with some oxygenated volatile organic compounds under simulated atmospheric conditions, Int. J. Chem. Kinet., 30, $839-847$.

Pilewskie, P., J. Pommier, R. Bergstrom, W. Gore, S. Howard, M. Rabbette, B. Schmid, P. V. Hobbs, and S. C. Tsay (2003), Solar spectral radiative forcing during the Southern African Regional Science Initiative, J. Geophys. Res., 108(D13), 8486, doi:10.1029/2002JD002411.

Platz, J., O. J. Nielsen, T. J. Wallington, J. C. Ball, M. D. Hurley, A. M. Straccia, W. F. Schneider, and J. Sehested (1998), Atmospheric chemistry of the phenoxy radical, $\mathrm{C}_{6} \mathrm{H}_{5} \mathrm{O}$ : UV spectrum and kinetics of its reaction with $\mathrm{NO}, \mathrm{NO}_{2}$, and $\mathrm{O}_{2}, J$. Phys. Chem. A, 102(41), 7964-7974.

Poppe, D., R. Koppmann, and J. Rudolph (1998), Ozone formation in biomass burning plumes: Influence of atmospheric dilution, Geophys. Res. Lett., 25(20), 3823-3826.

Pöschl, U., R. von Kuhlmann, N. Poisson, and P. J. Crutzen (2000), Development and intercomparison of condensed isoprene oxidation mechanisms for global atmospheric modeling, J. Atmos. Chem., 37, 29-52.

Prather, M., et al. (2001), Atmospheric chemistry and greenhouse gases, in Climate Change 2001: The Scientific Basis. Contribution of Working Group I to the Third Assessment Report of the Intergovernmental Panel on Climate Change, edited by J. T. Houghton et al., pp. 239-288, Cambridge Univ. Press, New York.

Radke, L. F., J. L. Stith, D. A. Hegg, and P. V. Hobbs (1978), Airborne studies of particles and gases from forest fires, J. Air Pollut. Control Assoc., 28, 30-34.

Radke, L. F., D. A. Hegg, P. V. Hobbs, J. D. Nance, J. H. Lyons, K. K.Laursen, R. E. Weiss, P. J. Riggan, and D. E. Ward (1991), Particulate and trace gas emissions from large biomass fires in North America, in Global Biomass Burning: Atmospheric, Climatic, and Biospheric Implications, edited by J. S. Levine, pp. 209-224, MIT Press, Cambridge, Mass.

Radke, L. F., D. E. Ward, and P. J. Riggan (2001), A prescription for controlling the air pollution resulting from the use of prescribed biomass fire: clouds, Int. J. Wildland Fire, 10, 103-111.

Ramaswamy, V., O. Boucher, J. Haigh, D. Hauglustaine, J. Haywood, G. Myhre, T. Nakajima, G. Y. Shi, and S. Solomon (2001), Radiative forcing of climate change, in Climate Change 2001: The Scientific Basis. Contribution of Working Group I to the Third Assessment Report of the 
Intergovernmental Panel on Climate Change, edited by J. T. Houghton et al., pp. 349-416, Cambridge Univ. Press, New York.

Ramazan, K. A., D. Syomin, and B. J. Finlayson-Pitts (2004), The photochemical production of HONO during the heterogeneous hydrolysis of $\mathrm{NO}_{2}$, Phys. Chem. Chem. Phys., 6, 3836-3843.

Reid, J. S., P. V. Hobbs, R. J. Ferek, D. R. Blake, J. V. Martins, M. R Dunlap, and C. Liousse (1998), Physical, chemical, and optical properties of regional hazes dominated by smoke in Brazil, J. Geophys. Res., 103(D24), 32,059-32,080.

Reid, J. S., P. V. Hobbs, A. L. Rangno, and D. A. Hegg (1999), Relationships between cloud droplet effective radius, liquid water content, and droplet concentration for warm clouds in Brazil embedded in biomass smoke, J. Geophys. Res., 104(D6), 6145-6153.

Reis, P. M., J. A. L. Silva, A. F. Palavra, J. J. R. F. da Silva, T. Kitamura, Y. Fujiwara, and A. J. L. Pombeiro (2003), Single-pot conversion of methane into acetic acid in the absence of $\mathrm{CO}$ and with vanadium catalysts such as amavadine, Angew. Chem. Int. Ed., 42(7), 821-823.

Sander, S. P., et al. (2003), Chemical kinetics and photochemical data for use in atmospheric studies, Evaluation number 14, JPL Publ., 02-25. (Available at http://jpldataeval.jpl.nasa.gov/)

Sandu, A., D. N. Daescu, and G. R. Carmichael (2003), Direct and adjoint sensitivity analysis of chemical kinetic systems with KPP: Part I - theory and software tools, Atmos. Environ., 37, 5083-5096.

Sillman, S., J. A. Logan, and S. C. Wofsy (1990), A regional scale model for ozone in the United States with subgrid representation of urban and power plant plumes, J. Geophys. Res., 95(D5), 5731-5748.

Sinha, P., P. V. Hobbs, R. J. Yokelson, I. T. Bertschi, D. R. Blake, I. J. Simpson, S. Gao, T. W. Kirchstetter, and T. Novakov (2003a), Emissions of trace gases and particles from savanna fires in southern Africa, J. Geophys. Res., 108(D13), 8487, doi:10.1029/2002JD002325.

Sinha, P., P. V. Hobbs, R. J. Yokelson, D. R. Blake, S. Gao, and T. W. Kirchstetter (2003b), Distributions of trace gases and aerosols during the dry biomass burning season in southern Africa, J. Geophys. Res., 108(D17), 4536, doi:10.1029/2003JD003691.

Sinha, P., L. Jaeglé, P. V. Hobbs, and Q. Liang (2004), Transport of biomass burning emissions from southern Africa, J. Geophys. Res., 109, D20204 doi:10.1029/2004JD005044.

Stamnes, K., S. Tsay, W. Wiscombe, and K. Jayaweera (1988), Numerically stable algorithm for Discrete-Ordinate-Method: Radiative transfer in multiple scattering and emitting layered media, Appl. Opt., 27(12), $2502-2509$

Stith, J. L., L. F. Radke, and P. V. Hobbs (1981), Particle emissions and the production of ozone and nitrogen oxides from the burning of forest slash, Atmos. Environ., 15, 73-82.

Swap, R. J., et al. (2002), The Southern African Regional Science Initiative (SAFARI 2000): overview of the dry season field campaign, $S$. Afr. $J$ Sci., 98, 125-130.

Swap, R. J., H. J. Annegarn, J. T. Suttles, M. D. King, S. Platnick, J. L. Privette, and R. J. Scholes (2003), Africa burning: A thematic analysis of the Southern African Regional Science Initiative (SAFARI 2000), J. Geophys. Res., 108(D13), 8465, doi:10.1029/2003JD003747.

Tabazadeh, A., M. Z. Jacobson, H. B. Singh, O. B. Toon, J. S. Lin, R. B Chatfield, A. N. Thakur, R. W. Talbot, and J. E. Dibb (1998), Nitric acid scavenging by mineral and biomass burning aerosol, Geophys. Res. Lett., 25(22), 4185-4188.

Tabazadeh, A., R. J. Yokelson, H. B. Singh, P. V. Hobbs, J. H. Crawford, and L. T. Iraci (2004), Heterogeneous chemistry involving methanol in tropospheric clouds, Geophys. Res. Lett., 31, L06114, doi:10.1029/ 2003GL018775.

Takagi, H., S. Hatakeyama, H. Akimoto, and S. Koda (1986), Formation of methyl nitrite in the surface reaction of nitrogen dioxide and methanol. 1. Dark reaction, Environ. Sci. Technol., 20(4), 387-393.

Takegawa, N., et al. (2003), Photochemical production of $\mathrm{O}_{3}$ in biomass burning plumes in the boundary layer over northern Australia, Geophys. Res. Lett., 30(10), 1500, doi:10.1029/2003GL017017.

Talukdar, R. K., T. Gierczak, D. C. McCabe, and A. R. Ravishankara (2003), Reaction of hydroxyl radical with acetone. 2. Products and reaction mechanism, J. Phys. Chem. A, 107, 5021-5032.
Tanaka, P. L., et al. (2003), Direct evidence for chlorine-enhanced urban ozone formation in Houston, Texas, Atmos. Environ., 37, 1393-1400.

Thompson, A. M., J. C. Witte, R. D. Hudson, H. Guo, R. R. Herman, and M. Fujiwara (2001), Tropical tropospheric ozone and biomass burning, Science, 291, 2128-2132.

Tomas, A., E. Villenave, and R. Lesclaux (2001), Reactions of the $\mathrm{HO}_{2}$ radical with $\mathrm{CH}_{3} \mathrm{CHO}$ and $\mathrm{CH}_{3} \mathrm{C}(\mathrm{O}) \mathrm{O}_{2}$ in the gas phase, J. Phys. Chem. A, 105, 3505-3514

Torres, O., P. K. Bhartia, J. R. Herman, A. Sinyuk, P. Ginoux, and B. Holben (2002), A long-term record of aerosol optical depth from TOMS observations and comparisons to AERONET measurements, J. Atmos. Sci., 59(3), 398-413.

Trentmann, J., M. O. Andreae, and H.-F. Graf (2003a), Chemical processes in a young biomass-burning plume, J. Geophys. Res., 108(D22), 4705, doi:10.1029/2003JD003732.

Trentmann, J., B. Früh, O. Boucher, T. Trautmann, and M. O. Andreae (2003b), Three-dimensional solar radiation effects on the actinic flux field in a biomass-burning plume, J. Geophys. Res., 108(D17), 4558, doi:10.1029/2003JD003422

Turn, S. Q., B. M. Jenkins, J. C. Chow, L. C. Pritchett, D. Campbell, T. Cahill, and S. A. Whalen (1997), Elemental characterization of particulate matter emitted from biomass burning: Wind tunnel derived source profiles for herbaceous and wood fuels, J. Geophys. Res., 102(D3), 3683-3699.

Tyndall, G. S., R. A. Cox, C. Granier, R. Lesclaux, G. K. Moortgat, M. J. Pilling, A. R. Ravishankara, and T. J. Wallington (2001), Atmospheric chemistry of small organic peroxy radicals, J. Geophys. Res., 106(D11), $12,157-12,182$

von Kuhlmann, R., M. G. Lawrence, P. J. Crutzen, and P. J. Rasch (2003), A model for studies of tropospheric ozone and non-methane hydrocarbons: Model description and ozone results, J. Geophys. Res., 108(D9), 4294, doi:10.1029/2002JD002893.

Wagner, V., M. E. Jenkin, S. M. Saunders, J. Stanton, K. Wirtz, and M. J. Pilling (2003), Modelling of the photooxidation of toluene: conceptual ideas for validating detailed mechanisms, Atmos. Chem. Phys., 3, 89106

Yokelson, R. J., I. T. Bertschi, T. J. Christian, P. V. Hobbs, D. E. Ward, and W. M. Hao (2003a), Trace gas measurements in nascent, aged, and cloudprocessed smoke from African savanna fires by airborne Fourier transform infrared spectroscopy, J. Geophys. Res., 108(D13), 8478, doi:10.1029/ 2002JD002322

Yokelson, R. J., T. J. Christian, I. T. Bertschi, and W. M. Hao (2003b), Evaluation of adsorption effects on measurements of ammonia, acetic acid, and methanol, J. Geophys. Res., 108(D20), 4649, doi:10.1029/ 2003JD003549.

Zdunkowski, W. G., W.-G. Panhans, R. M. Welch, and G. J. Korb (1982), A radiation scheme for circulation and climate models, Beitr. Phys. Atmos., $55,215-238$

Zhou, X., Y. He, G. Huang, T. D. Thornberry, M. A. Carroll, and S. B. Bertman (2002), Photochemical production of nitrous acid on glass sample manifold surface, Geophys. Res. Lett., 29(14), 1681, doi:10.1029/ 2002GL015080.

M. O. Andreae, Department of Biogeochemistry, Max Planck Institute for Chemistry, P.O. Box 3060, 55020 Mainz, Germany.

T. J. Christian and R. J. Yokelson, Department of Chemistry, University of Montana, Missoula, MT 59812, USA.

P. V. Hobbs and J. Trentmann, Department of Atmospheric Sciences, University of Washington, Box 351640, Seattle, WA 98195, USA. (phobbs@atmos.washington.edu; jtrent@uni-mainz.de)

S. A. Mason, Department of Chemistry, 220 Houghton Hall, SUNY College at Fredonia, Fredonia, NY 14063, USA

T. Winterrath, Deutscher Wetterdienst, Kaiserleistraße 29/35, 63067 Offenbach am Main, Germany. 